\title{
THE SYNTHESIS AND CHARACTERISATIONS OF POROUS THIOAMIDE-SULFONATED- MODIFIED POLY (ACRYLONITRILE-CO-DIVINYLBENZENE-80) AS A POTENTIAL SORBENT TO CAPTURE POLAR ANALYTES
}

Farhana Syakirah Ismail ${ }^{1}$, Siti Nurul Ain Md. Jamil ${ }^{1 *}$, Peter A. G. Cormack ${ }^{2}$, Luqman Chuah Abdullah ${ }^{3}$, Sazlinda Kamaruzaman ${ }^{1}$ and Rusli Daik ${ }^{4}$

${ }^{1}$ Department of Chemistry, Faculty of Science, Universiti Putra Malaysia, 43400 UPM Serdang, Selangor, Malaysia.

${ }^{2}$ WestCHEM, Department of Pure and Applied Chemistry, University of Strathclyde, Thomas Graham Building, 295 Cathedral Street, Glasgow G1 1XL, Scotland, U.K.

${ }^{3}$ Department of Chemical and Environmental Engineering, Faculty of Engineering, Universiti Putra Malaysia, 43400 UPM Serdang, Selangor, Malaysia.

${ }^{4}$ School of Chemical Sciences and Food Technology, Faculty of Science and Technology, Universiti Kebangsaan Malaysia,43600 Bangi, Selangor, Malaysia

*Corresponding author:

Siti Nurul Ain Md. Jamil

ctnurulain@upm.edu.my

\begin{abstract}
Pharmaceuticals contain biologically active components that can pollute water courses as a result of the excretions from individuals and/or uncontrolled release of residues from chemical plants, and they can pose a hazard to health. Pharmaceutical residues can persist at low concentrations in the environment, and thus may be potentially harmful to aquatic animals and to humans. Controlling and monitoring such residues are therefore a prime interest, for example, a solid-phase extraction uses solid sorbents to purify and preconcentrate the residues prior to their chemical analysis. In the present study, poly (acrylonitrile-co-divinylbenzene-80) sorbents are synthesised by varying the comonomer feed ratios under precipitation polymerisation conditions to deliver a family of porous polymer microspheres. Acrylonitrile confers polar characters onto the sorbents, and the acrylonitrile-derived nitrile groups can be chemically transformed via polymer-analogous reactions into thioamide and sulfonated residues which make the sorbents even more suitable for the capture of polar analytes, including selected pharmaceuticals. The utility of the porous thioamide-sulfonated containing sorbents is demonstrated via the dispersion-solid phase extraction of mefenamic acid from aqueous media; mefenamic acid is an anthranilic acid derivative which is a potent, nonsteroidal anti-inflammatory drug which is found in environmental waters at low concentrations.
\end{abstract}

\section{Keywords}

Polyacrylonitrile, chemical modification, thiourea, polar pharmaceuticals, sulphonation, dispersion-solid phase extraction 


\section{Introduction}

Pharmaceutical residues contain active ingredients that have been designed to have pharmacological effects and significant benefits to society. Pharmaceutical compounds may enter the environment by different routes such as discharge of treated wastewater, seepage from landfill sites, sewer lines and runoff from animal wastes [1, 2]. The issue of pharmaceutical residue disposal is a current concern among the public as it may eventually reduce water quality [3-7]. In addition, pharmaceuticals may be released into the effluents from poorly controlled manufacturing or production industries. The occurrence of pharmaceutical residues in the environment and water cycle at trace level greatly threatens human health and disrupts the ecosystem. Studies show that $70 \%$ of the pharmaceutical residues in waste water come from household, hospital and pharmaceutical industrial effluents [5, 8-10].

Table 1 shows the concentration of pharmaceuticals detected in Langat River in Malaysia. Targeted analytes were detected in river water samples at measurable concentration namely acetaminophen, atenolol, metformin, levonorgestrel, perindopril, chlorothiazide, diclofenac, furosemide, glibenclamide, gliclazide, mefenamic acid and salicylic acid. Metformin and chlorothiazide found in the surface water, were at relatively high concentrations of 293 and 182 $n g L^{-1}$, respectively. The lowest concentrations detected were for glibenclamide, perindopril and furosemide (2, 8 and $9 \mathrm{ngL}^{-1}$, respectively). STP effluents of amlodipine, cyproterone, loratadine, simvastatin, nifedipine, levonorgestrel and chlorpheniramine $\left(\mathrm{nLL}^{-1}\right)$ were not detected. The highest concentration detected was $865 \mathrm{ngL}^{-1}$ for chlorothiazide followed by metoprolol (364 $\left.\mathrm{ngL}^{-1}\right)$, diclofenac $\left(217 \mathrm{ngL}^{-1}\right)$, norethindrone $\left(188 \mathrm{ngL}^{-1}\right)$, mefenamic acid $\left(142 \mathrm{ngL}^{-1}\right)$ and atenolol $\left(107 \mathrm{ngL}^{-1}\right)$. The detection of these pollutants suggested incomplete eliminations of most of the targeted analytes by STP. Therefore, these pollutants were continuously discharged into the Langat River through STP effluents [11].

Mefenamic acid (MA) (Figure 1) is an anthranilic acid derivative which is a potent nonsteroidal anti-inflammatory drug (NSAID) of the enolic class [12]. It is used as antirheumatic and antipyretic analgesic, in the treatment of dental pain headache, postpartum and menstrual pain [13]. Mefenamic acid residues can be introduced into water sources through sewage, which carries excrement from individuals and patients who consumed the drug. Studies on antibiotics have shown that up to $95 \%$ of antibiotic compounds were released, without alteration into the sewage system, and high concentrations of antibiotics can lead to a change in the microbial community structure, which will ultimately affect food chains. 
Mefenamic acid is one of the pharmaceutical residues that may affect the aquatic environment and water supplement. In Malaysia, mefenamic acid was detected in Langat River in Selangor with a concentration of $146 \mathrm{ngL}^{-1}$ [11]. Although the detected concentrations of pharmaceuticals were low, the long term exposure of pharmaceuticals would pose health risks to humans, animals and aquatics [14].

Pharmaceutical residues can be removed from water through adsorption onto sludge in water treatments [15-18]. Research on the adsorptive removal of pharmaceutical residues from water have largely increased in recent years. Adsorption is a potential method for the removal of pharmaceutical residues due to its mild operation conditions, low energy consumption, and lack of side products [19-21]. Charcoal, which is obtained from the pyrolysis of primary pulp mill sludge, is proven to adsorb pharmaceutical residues (diclofenac, salicylic acid, ibuprofen and acetaminophen) from wastewater [22]. Carbonaceous materials (including activated carbon, and carbon nanotubes) and mesoporous materials (transition metal-graft) have been widely studied as potential adsorbents for the removal of pharmaceutical residues [20]. Molecularly imprinted polymer is also proven as a potential material for the reduction of matrix interferences and the selective extraction of acidic pharmaceuticals, such as salicylic acid, ibuprofen, fenoprofen, diclofenac and naproxen from effluent wastewater samples [23]. Furthermore, hypercrosslinked polymers with quaternary ammonium groups which act as an integral part of their structure (HXLPPSAX) have been applied as strong anionic exchange (SAX) sorbents in the solid phase extraction (SPE) to enable the selective extraction of acidic pharmaceuticals from environmental water samples. These sorbents have enabled the selective extraction of a group of acidic compounds from complex environmental water samples [19, 24].

Porous polymers are synthetic materials that are able to adsorb or desorb a wide range of compounds. Porous polymer particles have a great potential for applications in many fields, including as adsorbents, catalyst supports and matrices for the binding of sensitive materials with multilevel structures which consist of submicron-sized hollow cavities and interconnected mesopores within the crosslinked shell [25-27]. In this study, a series of imidazolium-based porous organic polymer (POP-Ims) was synthesised, and the porosities of such polymers were well tuned by varying the ratios of the two monomers. It was found that the POP-Ims with the highest density of imidazolium moiety (POP-Im1) exhibited the best dispersity in water and had the highest efficiency for removing $\mathrm{Cr}_{2} \mathrm{O}_{7}{ }^{-2}[28]$. 
Hypercrosslinked poly (styrene (PS)-co-divinybenzene(DVB)) sorbents with a high micropore content (specific surface area up to $2000 \mathrm{~m}^{2} \mathrm{~g}^{-1}$ ) were prepared to provide more interaction points with the analytes. The hydrophobic structure of the original porous polymers of poly (PS-co-DVB) was modified to generate hydrophilic and hypercrosslink parts on the sorbents. It was found that, $76-100 \%$ of the pharmaceutical residues were captured by the modified poly (PS-co-DVB) [29-32]. A preliminary study was carried out to investigate the potential of hypercrosslinked poly (acrylonitrile-co-divinylbenzene-co-vinylbenzylchloride) in the capture of polar pharmaceuticals, diclofenac from a polar environment [33]. In addition, chemical modifications of porous materials were carried out to enhance the selectivity of the adsorbents towards pharmaceuticals; for instance, the preparation of copolymer of bis[4(2hydroxy-3-methacryloyloxypropoxy) phenyl] sulfide and glycidyl methacrylate was modified from the reactions of the surface epoxide groups of the precursor with amines (butylenediamine and diethylenethriamine). The prepared copolymers were utilised as adsorbents in the solid phase extraction (SPE) of the multicomponent mixture of phenolic compounds [30].

Chitosan which was grafted with anionic groups such as sulfonate (CsSLF) and carboxylate (CsNCB) was made to adsorb pramipexole dihydrochloride (PRM). It was found that, at a high $\mathrm{pH}$, the adsorption of RPM towards CsNCB was high up to $82 \%$. However, the desorption of RPM from CsNCB was around $15 \%$ to $20 \%$ at the same $\mathrm{pH}$. The desorption from both CsNCB and CSSLF was high up to 95\% when the value of the $\mathrm{pH}$ was low (acid condition) [34].

However, the major disadvantages of these adsorbents were low adsorption capacities, relatively weak interactions with ions and difficulties of separation and regeneration from water for some of them. Ion-exchange resins were able to remove ions substantially; however, they had low selectivity and showed a high degree of swelling and poor mechanical stability [35].

To overcome these limitations, poly (AN-co-DVB-80) (Figure 2) was synthesised via precipitation polymerisation. The DVB-80 monomer acted as a crosslinking agent that helped to maintain the firmness and develop a three-dimensional molecule (and hence develop porosity) in the PAN copolymer system. The efficacy of the adsorption capacity was expected to improve with the development of the porosity of the PAN-based polymeric adsorbent. The porous resin had functioned upon its chemical treatment with thiourea (on the nitrile units) (Figure 3) to develop a basic anion exchanger of poly (AN-co-DVB-80) matrix. Thioamide was selected to instill three amine groups on each of the cyano group with longer pendant chains. The anion exchangers which carried cationic groups $\left(\equiv \mathrm{N}^{+},=\mathrm{NH}^{+}\right.$and $\left.-\mathrm{NH}_{2}{ }^{+}\right)$were 
expected to attach to the reversely charged counter ions by electrostatic interactions. In addition, sulphuric acid was introduced onto the thioamide-modified poly (AN-co-DVB80) by sulphonation (Figure 4) to increase the ion conductivity and induce stronger interactions with the polar compounds [36]. In the present study, a preliminary test to investigate the potential of the sorbent to capture polar analytes (mefenamic acid) was carried out via the dispersion-solid phase extraction (d-SPE) method. The anions of mefenamic acid (Figure 5) were expected to exchange with the adsorbents containing anion exchanger groups.

\section{Materials and methods}

\subsection{Materials and equipment}

The reagents used for the polymer synthesis were acrylonitrile (AN) and divinylbenzene (DVB-80) and both were purchased from Sigma-Aldrich (Dorset, UK). DVB-80 and acrylonitrile were purified by putting them through a short column of neutral alumina. The benzoyl peroxide (BPO) was used as a polymerisation initiator and was purchased from BDH (Poole, UK); prior to use, it was purified via recrystallisation from acetone at a low temperature. Acetonitrile, toluene and methanol were purchased from Sigma-Aldrich (Steinem, Germany). For the polymer-analogous reactions, thiourea and ethanol were supplied by SigmaAldrich (Dorset, UK), and sodium hydroxide was supplied by Systerm (India). For the sulphonation reaction, sulphuric acid was supplied by the Sigma-Aldrich (Dorset, UK). All other reagents were used as received.

Polymerisations were performed in Nalgene ${ }^{\circledR}$ plastic bottles. The bottles were placed in a Stuart Scientific S160 incubator (Surrey, UK) on a Stovall low profile roller (Essex, UK).

\subsection{Synthesis of poly (acrylonitrile-co-divinylbenzene-80)}

A series of poly (AN-co-DVB-80) microspheres was synthesised by copolymerising AN with DVB-80 using a range of AN to DVB-80 ratios, under precipitating polymerisation conditions. The porogen used was a mixture of acetonitrile and toluene $(150 \mathrm{~mL}$ and $50 \mathrm{~mL}$, respectively), and the total monomer concentration was fixed at $2 \% \mathrm{w} / \mathrm{v}$ relative to the solvent. The initiator concentration was fixed at $2 \mathrm{~mol} \%$, relative to the total number of polymerisable double bonds.

The Nalgene bottle was lightly sealed with Parafilm and placed in an ultrasonic bath for 30 minutes to degas the monomer solution. The monomer solution in the bottle was then 
deoxygenated by sparging with $\mathrm{N}_{2}$ at $0^{\circ} \mathrm{C}$ in an ice bath for 30 minutes. The bottle was then sealed under $\mathrm{N}_{2}$ and placed on a low-profile roller (Stovall, Essex, UK) in a temperature controllable incubator (Stuart Scientific, Surrey UK). The temperature was ramped from ambient temperature to $60^{\circ} \mathrm{C}$ over a period of around 2 hours, and then polymerisation was allowed to proceed at $60^{\circ} \mathrm{C}$ for a further 46 hours. The poly (AN-co-DVB-80) particles formed were isolated via vacuum filtration on a $0.2 \mu \mathrm{m}$ membrane filter and then washed in sequence with acetonitrile, toluene, methanol and acetone, before overnight drying in a vacuum oven at $40{ }^{\circ} \mathrm{C}$. The conversion of poly (AN), poly (DVB-80), and copolymers was calculated using eq. (1).

$$
\text { Monomer conversion }=\frac{\text { Weight of polymers }}{\text { Monomer feed }(g)} \times 100
$$

\subsection{Chemical modification of poly (AN-co-DVB-80) with thiourea}

The chemical modification of poly (AN-co-DVB-80) with thiourea took place at a ratio of 0.5:0.5 that is, AN: DVB-80. There were two stages involved in the chemical modification of the copolymer. The first stage was the hydrolysis of the poly (AN-co-DVB-80) in a NaOH solution in the following procedure; $0.3 \mathrm{~g}$ of copolymer particles and $10 \mathrm{~mL}$ of ethanol/water solution (molar ratio of 0.50$)$ containing $5 \%(\mathrm{w} / \mathrm{w})$ of $\mathrm{NaOH}$ were added into a $250 \mathrm{~mL}$ threenecked, round-bottomed flask. The mixture was stirred at $70{ }^{\circ} \mathrm{C}$ for 1 hour. The hydrolysed copolymer was filtered, rinsed with deionised water and dried overnight in a vacuum oven at $40^{\circ} \mathrm{C}$ until a constant weight was obtained.

The second stage took place by treating the copolymer with $10 \mathrm{~mL}$ of thiourea and water solution containing $3 \%(\mathrm{w} / \mathrm{w})$ of thiourea. The reaction was reported at $70^{\circ} \mathrm{C}$ for 2 hours. The hydrolysed thioamide poly (AN-co-DVB-80) was rinsed with deionised water until a neutral $\mathrm{pH}$ was achieved, then it was dried in a vacuum oven at $40^{\circ} \mathrm{C}$ until a constant weight was obtained. The modified copolymer was kept in a desiccator prior to further study.

\subsection{Sulphonation of the thioamide-modified poly (AN-co-DVB-80)}

The polymer particles and $\mathrm{H}_{2} \mathrm{SO}_{4}(98 \%)$ (1:5, weight to volume ratio) were added in a round bottomed flask and stirred by using a magnetic stirrer at $90{ }^{\circ} \mathrm{C}$ for 2 hours. The sulfonated polymer was then rinsed with deionised water and acetone until a neutral $\mathrm{pH}$ was achieved. The sulfonated polymer was kept in a desiccator after it was dried in a vacuum oven at $40{ }^{\circ} \mathrm{C}$ until a constant weight was obtained. 


\subsection{Batch adsorption of pharmaceuticals}

\subsubsection{Preparation of Standard Stock Solution}

$300 \mathrm{ppm}$ of the standard stock solution was prepared by weighing and transferring $150 \mathrm{mg}$ of mefenamic acid standard into a volumetric flask. Methanol was sufficiently added into the volumetric flask which gave a $500 \mathrm{~mL}$ solution.

\subsubsection{Procedures}

\subsubsection{Preparation of Standard Calibration Curve}

For the preparation of standard calibration curve, a series of mefenamic acid solutions (10, $20,30,40,50,60,70,80,90$ and $100 \mathrm{ppm}$ ) was accurately prepared by diluting the standard stock solution with methanol. These solutions were filtered by using a $0.45 \mathrm{~nm}$ nylon membrane before they were filled into $1 \mathrm{~mL}$ vial bottles. Standard solutions were injected into the HPLC system for analysis. A HPLC system (ACQUITY UPLC H-Class, USA) connected to a UV detector ( $285 \mathrm{~nm}$ wavelength) was used to measure the concentration of the APIs in elutes. The column C18 Xterra which measured $150 \mathrm{~mm}$ x $4 \mathrm{~mm}$ with $3 \mu \mathrm{m}$ particles was held at $35^{\circ} \mathrm{C}$. All analyses were performed with a flow rate $1.00 \mathrm{~mL} / \mathrm{min}$ and injection volume of 10 $\mu \mathrm{L}$. The APIs were separated using 50\% methanol as mobile phase (10 mins run time). The retention time of the highest peak was also recorded. Chromatograms obtained were analysed using an Empower software. A graph of absorbance against the concentration of mefenamic acid was plotted to determine the gradient.

\subsubsection{Preliminary analysis: Adsorption of mefenamic acid by using d-SPE}

The varying parameters for the adsorption included the concentration of mefenamic acid, sorbent dosage and contact time. Each analysis was repeated 5 times $(n=5)$.

The effect of mefenamic acid concentration on adsorption was investigated by adding 50 mg of poly (AN-co-DVB-80) sorbent into 15 different centrifuge tubes containing 20, 40, 60, $80,100,120,140,160,180,200,220,240,260,280$, and 300 ppm of aqueous mefenamic acid solutions, respectively. Similar steps were repeated for thioamide-modified poly (AN-co-DVB80 ) and thioamide- $\mathrm{HSO}_{3}$-modified poly (AN-co-DVB-80) sorbents. All the samples were left to equilibrate for 24 hours prior to the chromatography analysis. The sample solutions were centrifuged for five minutes at $4800 \mathrm{rpm}$ to ensure all the particles were sedimented. An aliquot of supernatant was also removed. Methanol was used as an elution solvent to elute the 
analytes from the solid sorbent. The mixture was then centrifuged for 5 minutes at $4800 \mathrm{rpm}$, which led to the settlement of the analytes and the solid sorbent at the bottom of the centrifuge tube. Finally, $1 \mathrm{~mL}$ of the solvent was taken out and injected into the HPLC system for analysis.

The effects of the adsorbent dosage were investigated by using different amounts of sorbents, whereby 10, 20,30, 40 and $50 \mathrm{mg}$ of sorbents were added into different centrifuge tubes containing $20 \mathrm{ppm}$ of mefenamic acid. Similar steps were repeated for thioamidemodified poly (AN-co-DVB-80) and thioamide- $\mathrm{HSO}_{3}$-modified poly (AN-co-DVB-80) sorbents. All the samples were left to equilibrate for 24 hours prior to a chromatography analysis.

The effects of contact time were investigated by varying the contact time for 1, 3, 6, 12 and 24 h. Similar steps were repeated for thioamide-modified poly (AN-co-DVB-80) and thioamide- $\mathrm{HSO}_{3}$-modified poly (AN-co-DVB-80) sorbents. All the samples were left to equilibrate overnight prior to a chromatography analysis.

\subsubsection{Determination of Adsorption Capacity}

The adsorption capacity was determined by using equation (2). The difference between the concentration of the mefenamic acid solution at the beginning and at equilibrium was used in the calculation:

$$
q_{e}=\frac{\left(C_{0} C_{e}\right) V}{m}
$$

where $C_{0}$ and $C_{e}$ were the initial and equilibrium concentration $(\mathrm{mg} / \mathrm{L})$ of the mefenamic acid, respectively; $V$ is the volume of the solution $(\mathrm{mL})$; and $m$ is the amount of adsorbent used $(\mathrm{g})$. The removal percentage can be calculated as:

$$
\text { Removal percentage }=\frac{\left(C_{0} C_{e}\right) \times 100}{C_{0}}
$$




\subsection{Characterisations}

\subsubsection{Fourier Transform Infrared (FTIR) Spectroscopy}

The Fourier Transform Infrared Spectra (FTIR) was analysed by a Spectrum BX Elmer spectrometer (U.S). FTIR was utilised to verify the presence of a certain functional group by the spectrum of copolymer. Samples were analysed by using an Attenuated Total Reflectance (ATR) within the range of $400-4000 \mathrm{~cm}^{-1}$ at $25^{\circ} \mathrm{C}$.

\subsubsection{Scanning Electron Microscope (SEM)}

SEM instrument (JEOL JSM 6360LA, Japan) was used to observe the morphologies of the copolymers and the chemically modified polymers. The steel stub was coated with a conductive copper using a double-sided adhesive tape. A thin layer of sample was then deposited onto the coated steel stub. The platinum coating of the immobilised sample was carried out for 8 minutes and a coated sample was placed inside the SEM chamber and a vacuum was applied. Micrographs were acquired at accelerating voltages of $10.0 \mathrm{kV}$ or 25.0 $\mathrm{kV}$. The microsphere diameters and particle size distributions were calculated using the Image $\mathrm{J}$ software from the SEM image analysis of 100 individual particles.

\subsubsection{Nitrogen Sorption Analysis}

The specific surface area, pore volumes and mean pore sizes of polymer microspheres were determined using a Micrometrics ASAP 2010 (United States) surface area analyser. Samples were degassed overnight under vacuum at $100^{\circ} \mathrm{C}$ and then analysed by using nitrogen sorption which was carried out at $77 \mathrm{~K}$.

\subsubsection{Elemental Microanalysis}

The number of carbon, hydrogen, nitrogen and sulphur were determined by using a Perkin Elmer 628 Series (United States). The samples were wrapped in tin foils and combusted at $1800^{\circ} \mathrm{C}$ in pure oxygen before they were catalysed. The interferences were removed from the combustion products before being swept into a detector zone where each element was separated and eluted as $\mathrm{CO}_{2}, \mathrm{H}_{2} \mathrm{O}, \mathrm{NO}_{2}$ and $\mathrm{SO}_{2}$. Then the signals were converted to percentage of elements. 


\section{Results and Discussions}

\subsection{Yields of the polymerisation of poly (AN-co-DVB-80)}

As tabulated in Table 2, poly (AN-co-DVB-80) was polymerised by varying the AN and DVB-80 ratios to $1.00: 0,0.80: 0.20,0.50: 0.50,0.40: 0.60,0.25: 0.75,0.20: 0.80$ and $0: 1.00$ (mol\%), respectively at 96 hours of reaction time. The observation during the precipitation polymerisations revealed that the homogeneous mixture (monomer, initiator and porogen) in the Nalgene bottle had started to form a milky white mixture after 90 to 120 minutes of heating in the incubator. However, the nucleation of poly (AN) cannot be observed in the Nalgene bottle due to the nature of poly (AN) that would dissolve in a mixture of acetonitrile and toluene.

Table 3 shows the yields of the polymerisation of poly (AN-co-DVB-80) which were collected by varying the ratio of AN:DVB-80 at a reaction time of 96 hours. The yields of the polymerisation of poly (AN-co-DVB-80) were in the range of $68.80-88.80 \%$ while the yields of the polymerisation of poly (AN) and poly (DVB-80) were $25.50 \%$ and $45.60 \%$, respectively. The lower yield of poly (AN) might be due to the absence of the crosslinking monomers (DVB-80) that would have facilitated the growth and stability of the particles in continuous phase during the polymerisation. It is noted that the half-life of the BPO is 1 hour at $92^{\circ} \mathrm{C}$ and 1 minute at $131^{\circ} \mathrm{C}$ [37]. Thus, BPO took a longer time to dissociate at $60^{\circ} \mathrm{C}$ and therefore, achieved more than $60 \%$ of yield but only at a reaction time of 96 hours.

\subsection{Fourier Transform Infrared Spectroscopy (FT-IR) analysis}

The FT-IR spectroscopic analysis was carried out to determine the presence of the desired functional group in order to confirm the success of the polymerisation of homopolymers and copolymers. Figure 6 shows the IR spectra of homopolymers which includes poly (AN) and poly (DVB-80). The IR spectrum of poly (AN) showed an intense absorption at $2255 \mathrm{~cm}^{-1}$ that corresponded to the stretching vibration of the nitrile group [38]. The adsorption band at 2960 $\mathrm{cm}^{-1}$ was assigned to the $\mathrm{C}-\mathrm{H}$ stretching vibration for $\mathrm{sp}^{3}$ carbon. The bending peak at 1462 $\mathrm{cm}^{1}$ was related to the bending vibration of $-\mathrm{CH}_{2}$ group [39]. The IR spectrum of poly (DVB80) showed a band at $1617 \mathrm{~cm}^{-1}$ that corresponded to the $\mathrm{C}=\mathrm{C}$ with stretching vibration from the aromatic ring [40]. The bands at $1458 \mathrm{~cm}^{-1}$ and $1425 \mathrm{~cm}^{-1}$ were assigned to the bending vibrations of $-\mathrm{CH}_{2}$ of the aliphatic compounds [41]. 
Figure 7 shows the comparison of IR spectra of poly (AN-co-DVB-80) with different ratios. The IR spectrum of poly (AN-co-DVB-80) revealed that there was an absorption band at $\sim 2234.68 \mathrm{~cm}^{-1}$ and it was assigned to the $\mathrm{CN}$ stretching vibration of the AN unit, which confirmed the AN incorporation [38, 41]. The intensity of the $\mathrm{CN}$ band increased as the amount of AN (mole \%) was increased in the feed. As shown in Figure 7, the strong band at the $\sim 2922.44 \mathrm{~cm}^{-1}$ region was due to the $\mathrm{C}-\mathrm{H}$ stretching vibration. The absorption at $\sim 1443.06$ $\mathrm{cm}^{-1}$ was related to the bending vibration band of imine groups $(\mathrm{C}=\mathrm{N})$. The hydrolysis of the nitrile groups would have occurred during polymerisation due to the presence of the active initiator radicals that contained oxygen atoms, and thus, would convert the nitrile group into imine group [41]. The absorption band at the region $\sim 1600.57 \mathrm{~cm}^{-1}$ was due to the carboncarbon stretching vibrations in the aromatic ring. Strong absorption band at $1700 \mathrm{~cm}^{-1}$ was due to the presence of the carbonyl $(\mathrm{C}=\mathrm{O})$ stretching vibrations [42]. The absorptions at $\sim 900 \mathrm{~cm}^{-1}$, $\sim 830 \mathrm{~cm}^{-1}$ and $\sim 790 \mathrm{~cm}^{-1}$ were due to the $\mathrm{C}-\mathrm{H}$ bonds in the benzene rings of meta $(\mathrm{m})$ and para $(p)$ in DVB units.

Figure 8 shows the FTIR spectra of poly (AN-co-DVB-80), hydrolysed poly (AN-co-DVB80 ) and thioamide-modified poly (AN-co-DVB-80) where AN: DVB-80 was set at a ratio of 0.5:0.5. The FTIR spectrum of hydrolysed poly (AN-co-DVB-80) showed a broad adsorption band at $\sim 3528 \mathrm{~cm}^{-1}$ which corresponded to the stretching vibration of the $\mathrm{OH}$ group and indicated the presence of $\mathrm{OH}$ groups on the poly (AN-co-DVB-80) chain structure. From the FTIR spectra, the CN group in the modified copolymer was diminished. A new peak was found at $\sim 3360.29 \mathrm{~cm}^{-1}$ in the modified copolymer spectrum, which would have corresponded to the stretching vibration of the $\mathrm{NH}_{2}$ groups. Another new strong peak appeared at $\sim 1052.47 \mathrm{~cm}^{-1}$ and it was assigned to the stretching vibrations of $\mathrm{C}=\mathrm{S}$ that confirmed the chemical modification of poly (AN-co-DVB-80) with thiourea to form thioamide-modified poly (ANco-DVB-80) [41].

Figure 9 shows the comparison of the IR spectra of poly (AN-co-DVB-80), thioamidemodified poly (AN-co-DVB-80) and thioamide- $\mathrm{HSO}_{3}$-modified poly (AN-co-DVB-80). In the case of sulphonated-modified copolymer, there was a new strong peak which appeared at $\sim 1154.47 \mathrm{~cm}^{-1}$ that was assigned to the stretching vibrations of $\mathrm{O}-\mathrm{SO}_{2}$. In addition, a new peak appeared at $\sim 1440.69 \mathrm{~cm}^{-1}$ that was assigned to the stretching vibrations of $\mathrm{O}-\mathrm{H}$. The appearance of new peaks confirmed the sulphonation reaction to thioamide-modified poly (AN-co-DVB-80). Table 4 shows the IR wavenumbers of poly (AN-co-DVB), thioamidemodified poly (AN-co-DVB-80) and thioamide- $\mathrm{HSO}_{3}$-modified poly (AN-co-DVB-80), respectively [43]. 


\subsection{Scanning Electron Microscope (SEM) Analysis}

The morphologies of homopolymers and copolymers were analysed using a Scanning Electron Microscope (SEM). Figure 10 shows the SEM images of homopolymers which are poly (AN) and poly (DVB-80) while Figure 11 shows the morphologies of poly (AN-co-DVB80) SEM images with different monomer ratios. Figure 12 shows the morphologies of the copolymer before and after the chemical modification with thiourea and also after sulfonation with sulphuric acid.

The appearance of poly (AN) in Figure 10 as clusters of agglomerated small particles could be due to the absence of DVB- 80 which contained residual double bonds that could capture the soluble oligomers and monomers and induce growth in the polymer particles and prevent coagulation during the polymerisation. The reaction would occur either between the active radicals and soluble oligomers or between the active radicals themselves due to the absence of crosslink monomers. As a result, aggregation or irregular particles were formed. In addition, the appearance of the aggregation of poly (AN) particles might be due to the process of evaporating the polymer solution in a room temperature overnight to recover the product and therefore, the soluble oligomers existed and appeared as small agglomerated particles in the SEM image.

Figure 11 shows that the spherical particles were afforded at AN fractions of $0,0.20,0.25$ and $0.40(\mathrm{~mole} \%)$ in the poly (AN-co-DVB- 80$)$ feed. Agglomerates of irregular particles and monolith-shape were formed at AN fractions of 0.50 and $0.80(\mathrm{~mole} \%)$ in the poly (AN-coDVB-80). As the amount of AN increased up to 0.8 (mole\%), the poly (AN-co-DVB-80) copolymers also precipitated quickly to stabilise against homocoagulation which could lead to the formation of aggregates of irregular particles. This was also due to the different solubility of DVB-80 and oligomers in a mixture of acetonitrile and toluene. The insufficient amount of DVB-80 served as a crosslinker which formed networks that provided mechanical stability for the polymers which then resulted in the collision between particles, consequently they produced small and agglomerated particles for the P33 and P34. The highest amount of AN in P34 resulted in the formation of copolymers with monolith structure.

The SEM images of poly (AN-co-DVB-80) showed that the incorporation of sufficient amount of DVB-80 such as $0.80 \mathrm{~mole} \%$ in the feed formed crosslinked copolymer chains in the copolymer system which influenced the stabilisation of particles against homocoagulation and afforded spherical shaped beads. The formation of irregular particles may be attributed to 
the poor solvation conditions for the involved monomers and might be due to the extended particle nucleation at low crosslinking content of 0.50 and 0.20 (mole $\%)$ in feed, respectively.

Table 5 depicts the mean particle diameters and particle size distributions of spherical particles that were determined using the Image $\mathbf{J}$ software. The mean diameter of the particles was calculated based on the average value measurement of 50 particle diameters from the SEM images (by using $\mathrm{J}$ Image software). As shown in Table 5, $\sigma$ is the standard deviation of the diameter and $\mu$ is the average particle diameter. The $C_{v}$ value was below $5 \%$ which indicated that the particles were monodispersed. The $C_{v}$ value of $5-15 \%$ was considered as quasimonodispersed particles. The $C_{v}$ value of above $15 \%$ indicated that the particles were polydisperse. Table 5 shows that P30, P31, P32 and P35 contained high amounts of DVB-80 in the feed $(1.00,0.80,0.75$, and 0.60 mole $\%$ of DVB-80), respectively, and appeared as polydisperse copolymers.

Figure 12 shows a comparison of the morphologies of the copolymer before and after a chemical modification with thiourea and also after sulfonation by sulphuric acid. Generally, the morphology of the modified copolymer as shown in Figure 10 is less agglomerated compared to its morphology before it is modified. In addition, Figure 12 shows that thioamide-modified poly (AN-co-DVB-80) and thioamide-HSO ${ }_{3}$-modified poly (AN-co-DVB-80) were less coarse and had a groovy appearance compared to poly (AN-co-DVB-80). This was due to the fact that modified copolymers comprised additional chains that contained thioamide groups and sulfonic groups; where the chains were attached to the copolymer surface and filled their pits. Generally, the P33 copolymer retained its particle structure even after the chemical modification with thiourea and sulphonation were carried out at high temperature.

\subsection{Brunauer-Emmett-Teller (BET) analysis}

Nitrogen sorption porosimetry is a useful technique to analyse the porosity of particles. The specific surface area was calculated using the Bruneuer-Emmett-Teller (BET) isotherm. Table 6 shows the nitrogen sorption porosimetry data which was obtained for poly (AN-co-DVB-80), thioamide-modified poly (AN-co-DVB-80) and thioamide- $\mathrm{HSO}_{3}$-modified poly (AN-co-DVB80).

In the present study, porogen (toluene) was introduced to acetonitrile as a reaction medium to develop porosity in the copolymer system. A higher incorporation of crosslinking monomer (DVB-80) in the feed during polymerisation of poly (AN-co-DVB-80) resulted in the 
formation of macro-reticular particles; while a higher incorporation of AN in the feed produced poly (AN-co-DVB-80) with gel-type appearance.

The increment of AN content during polymerisation resulted in lower porous surface area values and pore volume of copolymer system. The P30 with the lowest molar ratio of AN $(20 \%)$ had a surface area of $793 \mathrm{~m}^{2} \mathrm{~g}^{-1}$ while the P34 with the highest molar ratio of AN (80\%) had a surface area of $27 \mathrm{~m}^{2} \mathrm{~g}^{-1}$. Similar trend was seen in the pore volume; in which the pore volume of P30 and P34 were $0.823\left(\mathrm{~cm}^{3} \mathrm{~g}^{-1}\right)$ and $0.159\left(\mathrm{~cm}^{3} \mathrm{~g}^{-1}\right)$, respectively. The pore sizes of particles increased as the inclusion of AN was higher in the copolymer system. This was due to the lower inclusion of DVB-80 that resulted in less formation of crosslink networks in the particle system. It is a known fact that in the case of porous particles that a higher formation of crosslink networks would cause more porosity within the particles and consequently produce smaller pore sizes.

Table 7 reveals that the specific surface areas of P33 had decreased significantly; from 565 $\mathrm{m}^{2} \mathrm{~g}^{-1}$ to $330 \mathrm{~m}^{2} \mathrm{~g}^{-1}$ and $4 \mathrm{~m}^{2} \mathrm{~g}^{-1}$ after the chemical modifications were carried out with thiourea and sulphuric acid, respectively. This might be due to the introduction of new functional groups that had occupied the pores after the chemical modifications [44]. In addition, the chemical modification at elevated temperatures would have disrupted the pore wall and consequently reduced the pore volumes and surface area of the particles. The pore wall disruption was proven by the increment of the particle pore size from $5.8 \mathrm{~nm}$ (P33) to $7.0 \mathrm{~nm}$ (TP33) and $552.8 \mathrm{~nm}\left(\mathrm{TP} 33-\mathrm{HSO}_{3}\right)$. Although the surface area of the samples decreased upon modification by thiourea and sulphuric acid, the pore size was still large enough for the analytes to diffuse within the channels of the particles.

\subsection{Elemental Microanalysis}

The elemental microanalysis of CHNS is used to estimate the composition of the polymers isolated from the precipitation polymerisation. Table 8 shows the composition of carbon, hydrogen and nitrogen of the poly (AN), poly (DVB-80) and poly (AN-co-DVB-80) with different ratios. As expected, P35 poly (AN) had the highest amount of nitrogen (26\%) compared to the other polymers. P29 which is a DVB homopolymer showed $0 \%$ of nitrogen since no AN was present in the feed. In the case of poly (AN-co-DVB), as expected, the composition of nitrogen had increased as the amount of AN was increased in the feed. Generally, the percentage of the elements found in respective samples were according to the percentage of elements expected. 
Table 9 shows the composition of carbon, hydrogen, nitrogen and sulfur in P33, TP33 and TP33- $-\mathrm{HSO}_{3}$. As expected, P33 had no sulfur content at all. The TP33 had 4.1\% of sulfur content due to the chemical modification of the P33 with thiourea while the amount of sulfur in TP33- $\mathrm{HSO}_{3}$ was the highest (5.8\%) due to the sulphonation with sulphuric acid. As expected, the chemical modification of copolymer with thiourea had increased the amount of nitrogen in the TP33 (5.7\%) while TP33- $\mathrm{HSO}_{3}$ had the lowest content of nitrogen (3.3\%).

\subsection{The potential of sorbents in the capture of mefenamic acid}

The potential of sorbents in the capture of pharmaceuticals was evaluated by carrying out a preliminary analysis of mefenamic acid adsorption using poly (AN-co-DVB-80), thioamidemodified poly (AN-co-DVB-80) and thioamide- $\mathrm{HSO}_{3}$-modified poly (AN-co-DVB-80), respectively.

Figure 14 shows the amount of mefenamic acid that was adsorbed by the poly (AN-coDVB-80), thioamide-modified poly (AN-co-DVB-80) and thioamide- $\mathrm{HSO}_{3}$-modified poly (AN-co-DVB-80), respectively. The data demonstrated that, as the concentration of the pharmaceutical increased, the amount of pharmaceuticals adsorbed by the adsorbent had also increased until it achieved equilibrium. As shown in the Figure 14(a) and (b), the maximum amount of mefenamic acid adsorbed by the poly (AN-co-DVB-80) was $55.91 \mathrm{mgg}^{-1}$ (46.59\%); which was lower compared to the adsorption capacities of thioamide-modified poly (AN-coDVB-80) and thioamide- $\mathrm{HSO}_{3}$-modified poly (AN-co-DVB-80). A higher adsorption capacity of thioamide-modified poly (AN-co-DVB-80) $\left(93.88 \mathrm{mgg}^{-1}(78.23 \%)\right.$ ) was expected due to its high specific surface area $\left(330 \mathrm{~m}^{2} \mathrm{~g}^{-1}\right)$. On the other hand, thioamide- $\mathrm{HSO}_{3}$-modified poly (ANco-DVB-80) demonstrated the highest adsorption capacity $\left(96.88 \mathrm{mgg}^{-1}(80.73 \%)\right)$ despite its low specific surface area $\left(4 \mathrm{~m}^{2} \mathrm{~g}^{-1}\right)$. Thioamide-modified poly (AN-co-DVB-80) and thioamide$\mathrm{HSO}_{3}$-modified poly (AN-co-DVB-80) would have provided active functional groups to capture mefenamic acid despite their lower surface areas of $330 \mathrm{~m}^{2} \mathrm{~g}^{-1}$ and $4 \mathrm{~m}^{2} \mathrm{~g}^{-1}$, respectively, compared to the poly (AN-co-DVB-80) with the highest specific surface area of $565 \mathrm{~m}^{2} \mathrm{~g}^{-1}$. In the case of thioamide- $\mathrm{HSO}_{3}$-modified poly (AN-co-DVB-80), the development of thioamide and sulfur polar functional group provided longer pendant chains which increased the possibility of interactions between active functional groups and mefenamic acid during adsorption. An equilibrium was achieved at a concentration of $300 \mathrm{ppm}$ of mefenamic acid due to the fact that the active sites of the copolymer were fully occupied and had achieved a saturation level with the mefenamic acid molecules. 
Poly (AN-co-DVB-80), thioamide-modified poly (AN-co-DVB-80) and thioamide- $\mathrm{HSO}_{3}$ modified poly (AN-co-DVB-80) were respectively brought into contact with $20 \mathrm{ppm}$ of mefenamic acid by varying the sorbents' dosage (10 to $50 \mathrm{mg})$. As shown in Figure 15, the concentration of mefenamic acid adsorbed was increased as the adsorbent dosage increased. This was attributed to the higher number of active sites that captured the analytes [45]. Figure 15 demonstrates that the maximum adsorption of mefenamic acid was achieved by using thioamide- $\mathrm{HSO}_{3}$-modified poly (AN-co-DVB-80) sorbent at $96.88 \mathrm{mgg}^{-1}$ (80.73\%) of adsorption capacity.

The relationship between the contact time and the amount of mefenamic acid adsorbed is shown in Figure 16. The contact time of the adsorption was gradually increased from $1 \mathrm{~h}$ before it reached an equilibrium at $12 \mathrm{~h}$. The adsorption had risen with the increase of contact time due to a large number of vacant surface sites (of the sorbent) which was available at the initial stage. After a lapse of time, the remaining vacant surface sites of the sorbent would not be occupied easily due to the repulsive force between the solute molecules in the solid and bulk phase [45]. As shown in Figure 16, the maximum adsorption of the mefenamic acid at 12 $\mathrm{h}$ was achieved by thioamide-HSO 3 -modified poly (AN-co-DVB-80) (4.84 $\mathrm{mgg}^{-1}, 60.49 \%$ ).

The preliminary analysis was carried out by using the d-SPE method and it showed that the thioamide- $\mathrm{HSO}_{3}$-modified poly (AN-co-DVB-80) sorbent had captured the highest amount of mefenamic acid compared to the poly (AN-co-DVB-80) and thioamide-modified poly (ANco-DVB-80) sorbents. This observation indicated that the development of active functional groups (amides and sulphur polar functional groups) in thioamide- $\mathrm{HSO}_{3}$-modified poly (ANco-DVB-80) had facilitated the adsorption process; in which the adsorption capacity was comparable to the sorbent without multiple active functional groups but had the highest specific surface areas (thioamide-modified poly(AN-co-DVB-80)). It is noted that although the poly (AN-co-DVB-80) sorbent readily contains polar functional groups (cyano groups), it is necessary to chemically modify the sorbent to manipulate the cyano functional groups for selectivity purpose in future work.

\section{Conclusion}

The chemical modification of porous poly (AN-co-DVB-80) adsorbent was successfully carried out to develop anionic exchanger characteristics in the copolymer system. The specific surface area of poly (AN-co-DVB-80) particles was $565 \mathrm{~m}^{2} \mathrm{~g}^{-1}$ with a pore size of $5.8 \mathrm{~nm}$. The specific surface area of the thioamide-modified poly (AN-co-DVB-80) was 330 
$\mathrm{m}^{2} \mathrm{~g}^{-1}$ which was lower than the copolymer. The sulphonation resulted in even lower specific surface area $\left(4 \mathrm{~m}^{2} \mathrm{~g}^{-1}\right)$. The evaluation of the potential of the adsorbent in the capture of polar compounds was carried out by using mefenamic acid as analytes in the d-SPE system. The adsorption analysis showed that the thioamide- $\mathrm{HSO}_{3}$-modified poly (AN-co-DVB-80) had comparable adsorption capacity to the thioamide-modified poly (AN-co-DVB-80); although thioamide- $\mathrm{HSO}_{3}$-modified poly (AN-co-DVB-80) had lower specific area $\left(4 \mathrm{~m}^{2} \mathrm{~g}^{-1}\right)$ compared to the thioamide-modified poly (AN-co-DVB-80) $\left(330 \mathrm{~m}^{2} \mathrm{~g}^{-1}\right)$ and poly (AN-co-DVB-80) (565 $\left.\mathrm{m}^{2} \mathrm{~g}^{-1}\right)$. This finding showed that in addition to high specific surface areas, the development of thioamide and sulphur moieties in the copolymer system (a need for the instillation of anionic exchanger characteristics) had also facilitated the performance of the sorbent in the capture of the polar analytes.

\section{Acknowledgements}

The authors would like to thank the Chemistry Department of the Faculty of Science in Universiti Putra Malaysia (UPM) and WestCHEM of the Department of Pure and Applied Chemistry in the University of Strathclyde in the United Kingdom, and the Ministry of Higher Education of Malaysia for the financial support given via the Fundamental Research Grant Scheme (FRGS/1/2016/TK05/UPM/02/1). 


\section{References}

1. Patneedi, C.B. and K. Durga Prasadu, Impact of pharmaceutical wastes on human life and environment. Rasayan Hournal Chemical, 2015. 8: p. 67-70.

2. $\quad$ Shukla, T., et al., Role of Pharmacist In Pharmaceutical Waste Management. Vol. 6. 2017. 1-13.

3. Yakubu, O.H., Pharmaceutical Wastewater Effluent-Source of Contaminants of Emerging Concern: Phytotoxicity of Metronidazole to Soybean (Glycine max). Toxics, 2017. 5(2): p. 10.

4. Alshakka, M., et al., Hazards of Pharmaceuticals in Water as New Area in EcoPharmacovigilance Research. Journal of Pharmacy Practice and Community Medicine, 2016. 2(1): p. 3-8.

5. Olarinmoye, O., et al., Quantification of pharmaceutical residues in wastewater impacted surface waters and sewage sludge from Lagos, Nigeria. Journal of Environmental Chemistry and Ecotoxicology, 2016. 8(3): p. 14-24.

6. Zhou, H., et al., Occurrence and preliminarily environmental risk assessment of selected pharmaceuticals in the urban rivers, China. Scientific Reports, 2016. 6: p. 34928.

7. Baresel, C., et al., Pharmaceutical Residues and Other Emerging Substances In The Effluent of Sewage Treatment Plants. 2015, IVL Swedish Environmental Research Institute. p. 1-117.

8. Al-Odaini, N., et al., Detecting Human Pharmaceutical Pollutants in Malaysian Aquatic Environment: A new challenge for water quality management. 2011.

9. Bagheri, H., A. Afkhami, and A. Noroozi, Removal of Pharmaceutical Compounds from Hospital Wastewaters Using Nanomaterials: $A$ Review. Analytical and Bioanalytical Chemistry Research, 2016. 3(1): p. 1-18.

10. Białk-Bielińska, A., et al., Selected analytical challenges in the determination of pharmaceuticals in drinking/marine waters and soil/sediment samples. Journal of Pharmaceutical and Biomedical Analysis, 2016. 121: p. 271-296.

11. Al-Odaini, N.A., et al., Multi-residue analytical method for human pharmaceuticals and synthetic hormones in river water and sewage effluents by solid-phase extraction and liquid chromatography-tandem mass spectrometry. Journal of Chromatography A, 2010. 1217(44): p. 6791-6806.

12. Karaman, R., Abu-Jaish A., Mecca G., Jumaa S., Thawabteh A., Karaman R. "Mefenamic acid Prodrugs and Codrugs- Two Decades of Development" World Journal of Pharmaceutical Research 2015, 4(6): 2408-2429. 2015.

13. Abbas, N., D.I. Oswald, and R.C. Pulham, Accessing Mefenamic Acid Form II through High-Pressure Recrystallisation. Pharmaceutics, 2017. 9(2). 
14. Patneedi, C.B. and K.D. Prasadu, Impact of pharmaceutical wastes on human life and environment Rasayan journal Chem, 2015. 8(1): p. 67-70.

15. Kinney, C., et al., Presence and Distribution of Wastewater-Derived Pharmaceuticals in Soil Irrigated with Reclaimed Water. Vol. 25. 2006. 317-26.

16. Loos, G., A. Van Schepdael, and D. Cabooter, Quantitative mass spectrometry methods for pharmaceutical analysis. Philosophical transactions. Series A, Mathematical, physical, and engineering sciences, 2016. 374(2079): p. 20150366.

17. Madikizela, L.M. and L. Chimuka, Simultaneous determination of naproxen, ibuprofen and diclofenac in wastewater using solid-phase extraction with high performance liquid chromatography. Water SA, 2017. 43: p. 264-274.

18. Yao, Z., et al., Magnetic microsphere-based portable solid phase extraction device for on-site pre-concentration of organics from large-volume water samples. Scientific Reports, 2017. 7(1): p. 8069.

19. Khalik, W. and P. Abdullah, Solid Phase Extraction Method for Caffeine Analysis in Water: A Mini Review. Vol. 3. 2017. 485-489.

20. Seo, P.W., et al., Adsorptive Removal of Pharmaceuticals and Personal Care Products from Water with Functionalized Metal-organic Frameworks: Remarkable Adsorbents with Hydrogen-bonding Abilities. Scientific Reports, 2016. 6: p. 34462.

21. Deniz, D.a., Automatic capillary liquid chromatography tandem mass spectrometry method for pharmaceutical products in environmental water samples, in Det matematisk-naturvitenskapelige fakultet. 2017, Kjemisk institutt: Kjemisk institutt.

22. Coimbra, R.N., et al., Removal of pharmaceuticals from municipal wastewater by adsorption onto pyrolyzed pulp mill sludge. Arabian Journal of Chemistry, 2015.

23. Gilart, N., et al., Determination of pharmaceuticals in wastewaters using solid-phase extraction-liquid chromatography-tandem mass spectrometry. Journal of Separation Science, 2012. 35(7): p. 875-882.

24. Bratkowska, D., et al., Hypercrosslinked strong anion-exchange resin for extraction of acidic pharmaceuticals from environmental water. Journal of Separation Science, 2012. 35(19): p. 2621-2628.

25. Chen, D., et al., Super-adsorbent material based on functional polymer particles with a multilevel porous structure. Npg Asia Materials, 2016. 8: p. e301.

26. Ghosh, S.K., et al., Porous polymer composite membrane based nanogenerator: A realization of self-powered wireless green energy source for smart electronics applications. Journal of Applied Physics, 2016. 120(17): p. 174501.

27. Liu, L., et al., Porous polymer microneedles with interconnecting microchannels for rapid fluid transport. RSC Advances, 2016. 6(54): p. 48630-48635. 
28. Su, Y., et al., Imidazolium-Based Porous Organic Polymers: Anion Exchange-Driven Capture and Luminescent Probe of Cr2O72-. ACS Applied Materials \& Interfaces, 2016. 8(29): p. 18904-18911.

29. Fontanals, N., et al., Mixed-mode ion-exchange polymeric sorbents: dual-phase materials that improve selectivity and capacity. TrAC Trends in Analytical Chemistry, 2010. 29(7): p. 765-779.

30. Sobiesiak, M., B. Podkościelna, and P. Podkościelny, New functionalised polymeric microspheres for multicomponent solid phase extraction of phenolic compounds. Adsorption, 2016. 22(4): p. 653-662.

31. Tan, L. and B. Tan, Hypercrosslinked porous polymer materials: design, synthesis, and applications. Chemical Society Reviews, 2017. 46(11): p. 3322-3356.

32. Hwang, K.S., et al., Preparation of hypercrosslinked poly $(D V B-V B C)$ particles with high surface area and structured meso- and micropores. Macromolecular Research, 2015. 23(11): p. 1051-1058.

33. Subri, N.N.S., et al., Synthesis of poly(acrylonitrile-co-divinylbenzene-co-vinylbenzyl chloride)-derived hypercrosslinked polymer microspheres and a preliminary evaluation of their potential for the solid-phase capture of pharmaceuticals. Journal of Applied Polymer Science, 2017. 135(2): p. 45677.

34. Amouzgar, P., et al., Advanced Material for Pharmaceutical Removal from Wastewater. 2016. 179-212.

35. Samiey, B., C.-H. Cheng, and J. Wu, Organic-Inorganic Hybrid Polymers as Adsorbents for Removal of Heavy Metal Ions from Solutions: A Review. Materials, 2014. 7(2): p. 673-726.

36. Patiño, D., E. Correa, and M. Acevedo-Morantes, Effect of sulfonation and diethanolamine addition on the mechanical and physicochemical properties of SEPS copolymer. Journal of Physics: Conference Series, 2016. 687(1): p. 012056.

37. Hamid Hamdu, H., An isocratic normal-phase high-performance liquid chromatographic method for the simultaneous determination of benzoyl peroxide and benzoic acid in one pharmaceutical preparation and their stability in different solvents. Vol. 9. 2014. 04-12.

38. Gonz, M., et al., Synthesis and Study of Chemical, Thermal, Mesomorphic, and Optical Properties of Terphenyls Modified with Nitrile Groups. Journal of Chemistry, 2017. 2017: p. 9.

39. Oleszko, A., et al., Application of FTIR-ATR Spectroscopy to Determine the Extent of Lipid Peroxidation in Plasma during Haemodialysis. BioMed Research International, 2015. 2015: p. 245607.

40. Yoshida, S., Quantitative evaluation of an epoxy resin dispersion by infrared spectroscopy. Polymer Journal, 2014. 46: p. 430. 
41. Bagheri, B., et al., Efficient Removal of $\mathrm{Cr} 3+, \mathrm{Pb} 2+$ and $\mathrm{Hg} 2+$ Ions from Industrial Effluents by Hydrolyzed/Thioamidated Polyacrylonitrile Fibres. Vol. 19. 2010. 911925.

42. Mecozzi, M. and E. Sturchio, Computer Assisted Examination of Infrared and Near Infrared Spectra to Assess Structural and Molecular Changes in Biological Samples Exposed to Pollutants: A Case of Study. Journal of Imaging, 2017. 3(1).

43. Ge, S., et al., Adsorption characteristics of sulfur solution by acticarbon against drinking-water toxicosis. Saudi Journal of Biological Sciences, 2017. 24(6): p. 13551360 .

44. Ruimin, M., et al., Improving lead adsorption through chemical modification of wheat straw by lactic acid. IOP Conference Series: Earth and Environmental Science, 2018. 108(2): p. 022063.

45. de Andrade, J.R., et al., Adsorption of Pharmaceuticals from Water and Wastewater Using Nonconventional Low-Cost Materials: A Review. Industrial \& Engineering Chemistry Research, 2018. 57(9): p. 3103-3127. 


\section{List of Figures}

1. Figure 1 Mefenamic acid

2. Figure 2 The synthesis of poly (AN-co-DVB-80)

3. Figure 3 Chemical modification of poly (AN-co-DVB-80) with thiourea

4. Figure 4 Sulphonation of thioamide-modified poly (AN-co-DVB-80) with sulphuric acid

5. Figure 5 Anions of mefenamic acid

6. Figure 6 IR Spectra of poly (AN) and poly (DVB-80)

7. Figure 7 IR Spectra of the poly (AN-co-DVB-80) with different ratios

8. Figure 8 IR Spectra of the poly (AN-co-DVB-80), hydrolysed poly (AN-co-DVB-80) and thioamide-modified poly (AN-co-DVB-80)

9. Figure 9 IR Spectra of poly (AN-co-DVB-80), thioamide-modified poly (AN-co-DVB$80)$ and thioamide-modified poly (AN-co-DVB-80)-HSO3

10. Figure 10 SEM images of poly (AN) and poly (DVB-80)

11. Figure 11 SEM images of poly (AN-co-DVB-80) with different AN/DVB-80 ratios

12. Figure 12 SEM images of poly (AN-co-DVB-80), thioamide-modified poly (AN-coDVB-80), and thioamide-modified poly (AN-co-DVB-80)-HSO3

13. Figure 13 Polynomial Data of (a) P30, (b) P31 and (c) P32

14. Figure 14 Amount of (a) adsorption capacity, (b) percentage of mefenamic acid that was absorbed by the adsorbent at different concentrations

15. Figure 15 Amount of mefenamic acid that was absorbed by the thioamide-modified poly (AN-co-DVB-80) at different mass of adsorbent dosage

16. Figure 16 Amount of mefenamic acid that was absorbed by the adsorbent at different contact time 


\section{List of Tables}

1. Table 1 Concentration of pharmaceuticals detected in Langat River and STPs effluents $\left(\mathrm{ngL}^{-1}\right)$

2. Table 2 Monomers in feed for the synthesis of poly (AN-co-DVB-80) in a mixture of acetonitrile and toluene

3. Table 3 Yields of polymerisation of poly (AN-co-DVB-80) with different ratios

4. Table 4 IR wavenumber of poly (AN-co-DVB-80), thioamide-modified poly (AN-coDVB-80) and thioamide-modified poly (AN-co-DVB-80)-HSO3

5. Table 5 Size and dispersity of poly (AN), poly (DVB-80) and poly (AN-co-DVB-80)

6. Table 6 BET data of the poly (AN-co-DVB-80) with different ratios

7. Table 7 BET data of the poly (AN-co-DVB-80), thioamide-modified poly (AN-coDVB-80) and thioamide- $\mathrm{HSO}_{3}$-modified poly (AN-co-DVB-80)

8. Table 8 Elemental Microanalysis data of poly (AN), poly (DVB80) and poly (AN-coDVB-80) with different ratios

9. Table 9 Elemental Microanalysis data of poly (AN-co-DVB-80), thioamide-modified poly (AN-co-DVB-80), and thioamide- $\mathrm{HSO}_{3}$-modified poly (AN-co-DVB-80) 
<smiles>Cc1cccc(Nc2ccccc2C(=O)O)c1C</smiles>

Figure 1 Mefenamic acid

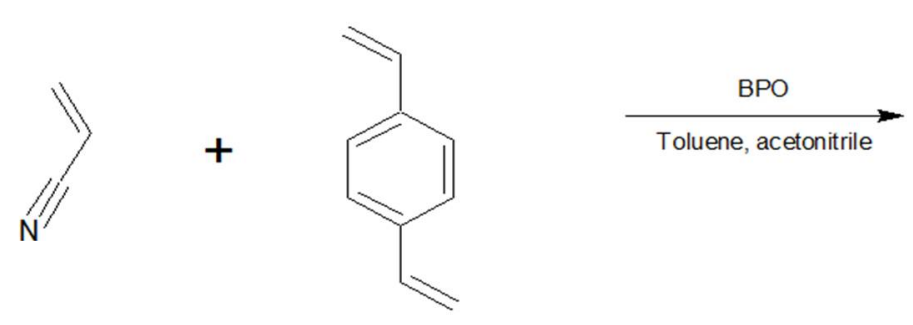

Divinylbenzne (DVB)

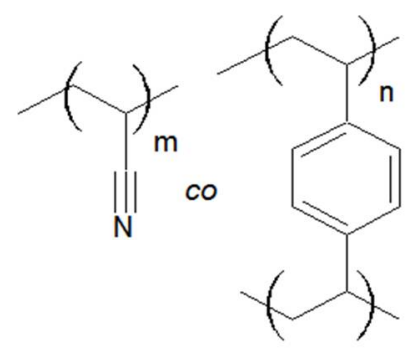

poly(AN co DVB)

Figure 2 The synthesis of poly (AN-co-DVB-80)<smiles>Cc1cc(C(C)C)ccc1C(C)CC(C)C(C)C</smiles>

poly(AN co DVB80)<smiles>CC(C)C(C(=N)NC(N)=S)C(C)(C)C</smiles><smiles>CCC(C)c1ccc(C(CC)C(C)C)cc1</smiles>

thioamide modified poly(AN co DVB80)

Figure 3 Chemical modifications of poly (AN-co-DVB-80) with thiourea 
<smiles>CC(C)(C)C(C(=N)NC(N)=S)C(C)(C)C</smiles><smiles>CC(C)C(c1ccc(C(CC(C)(C)C)C(C)(C)C)cc1)C(C)C</smiles><smiles>O=S(=O)(O)O</smiles>
$\mathrm{H}_{2} \mathrm{SO}_{4}$<smiles>[X]C(C)(C)CC(C)C(=N)NC(=S)NS(=O)(=O)O</smiles>
thioamide modified poly(AN co DVB80)- $\mathrm{H}_{2} \mathrm{SO}_{4}$

Figure 4 Sulphonation of thioamide-modified poly (AN-co-DVB-80) with sulphuric acid<smiles>C=C=C[O-]</smiles>

Figure 5 Anions of mefenamic acid

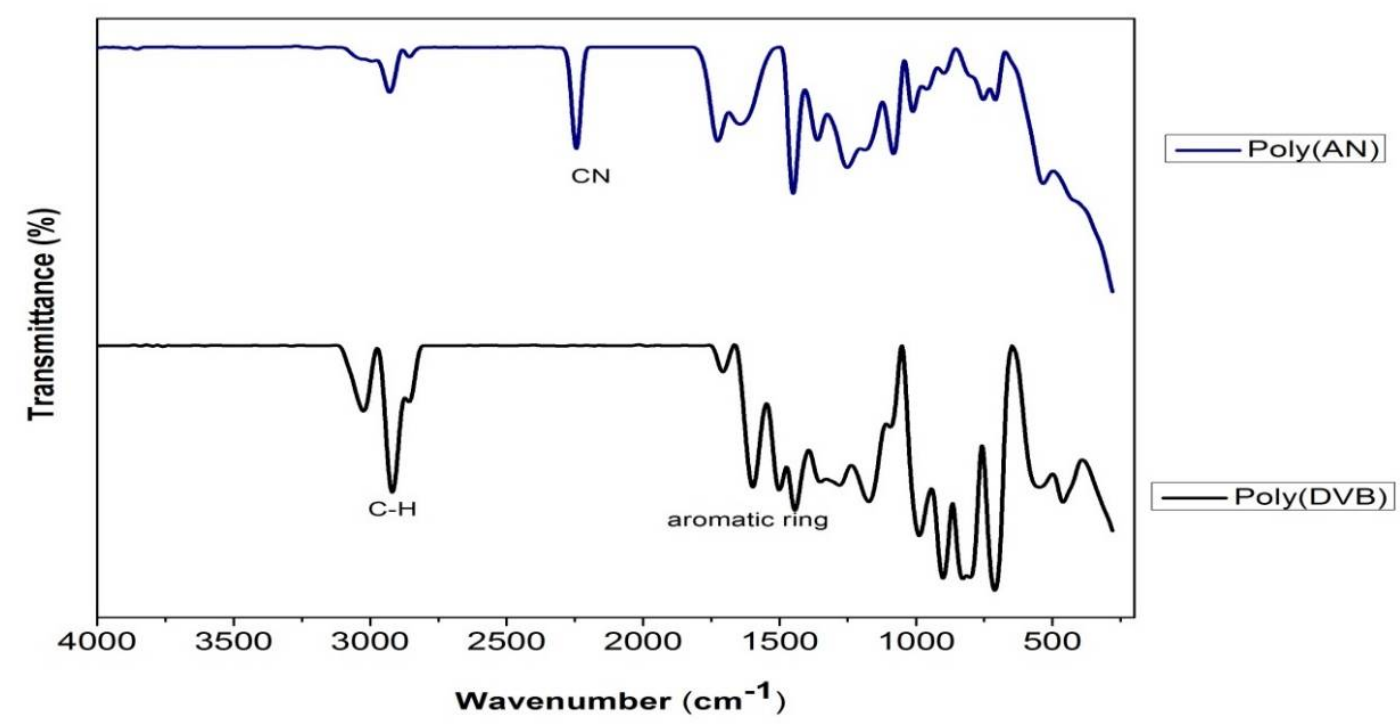

Figure 6 IR Spectra of poly (AN) and poly (DVB-80) 

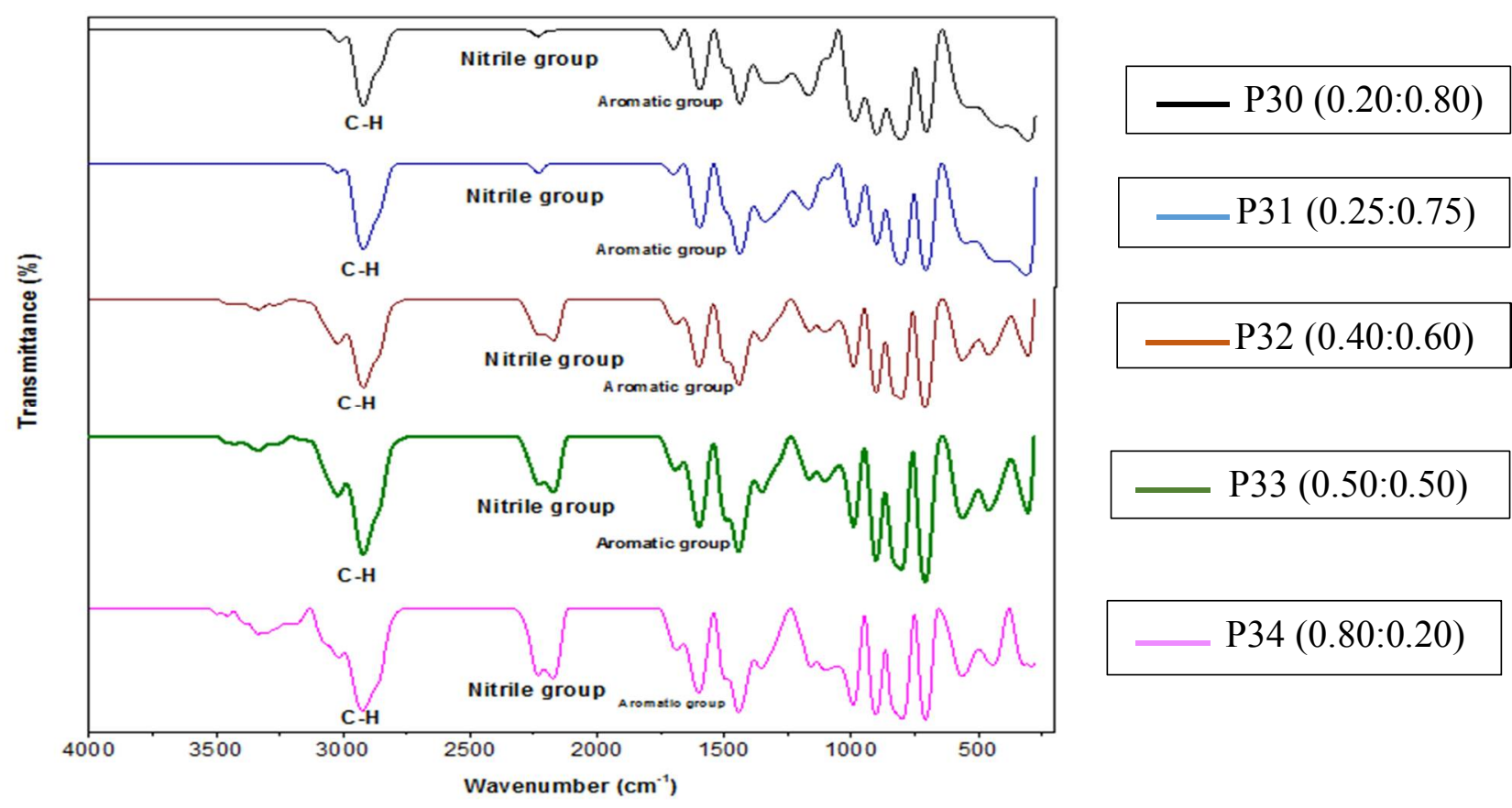

Figure 7 IR Spectra of the poly (AN-co-DVB-80) with different ratios

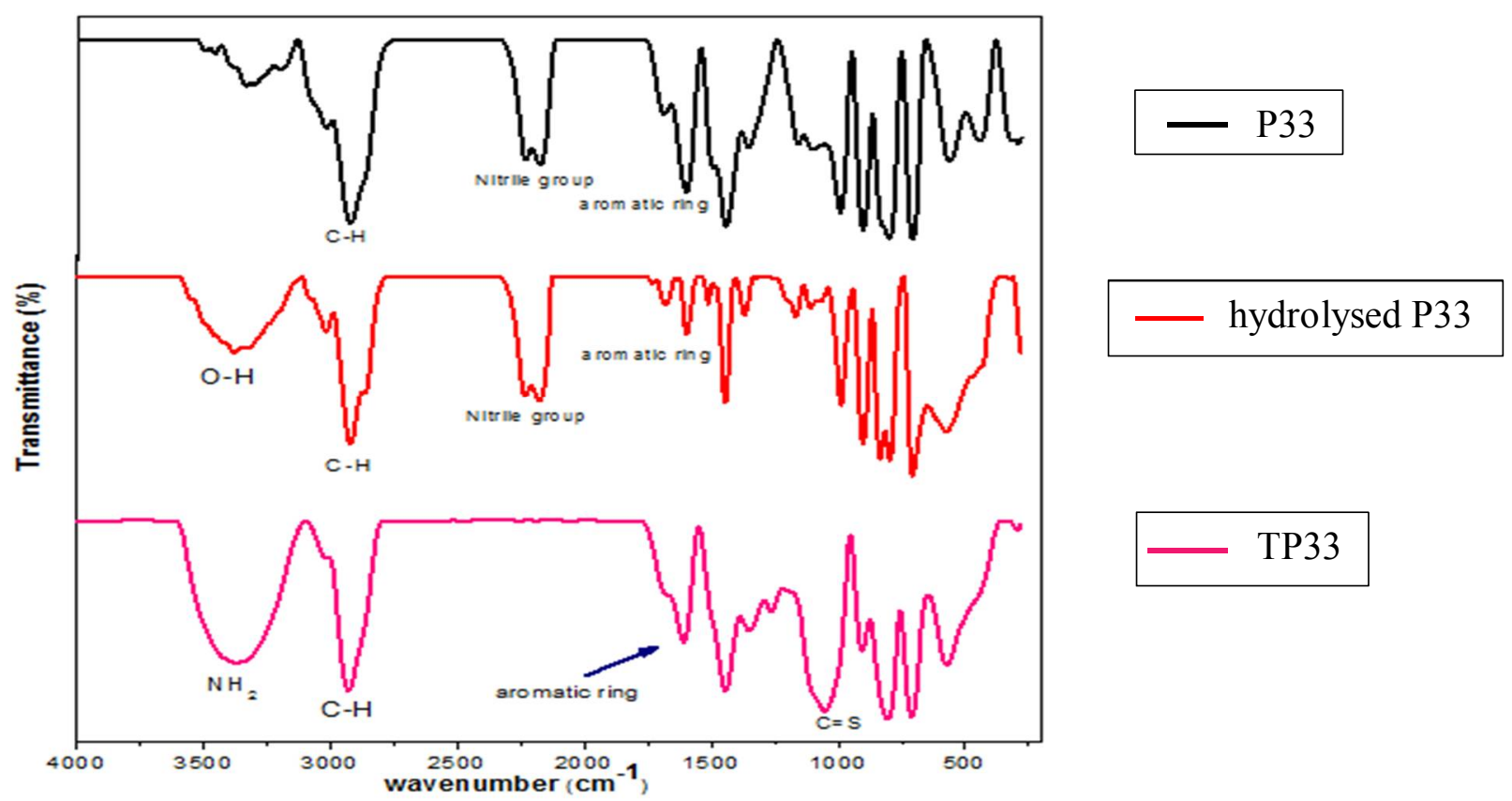

Figure 8 IR Spectra of the poly (AN-co-DVB-80), hydrolysed poly (AN-co-DVB-80) and thioamide-modified poly (AN-co-DVB-80) 

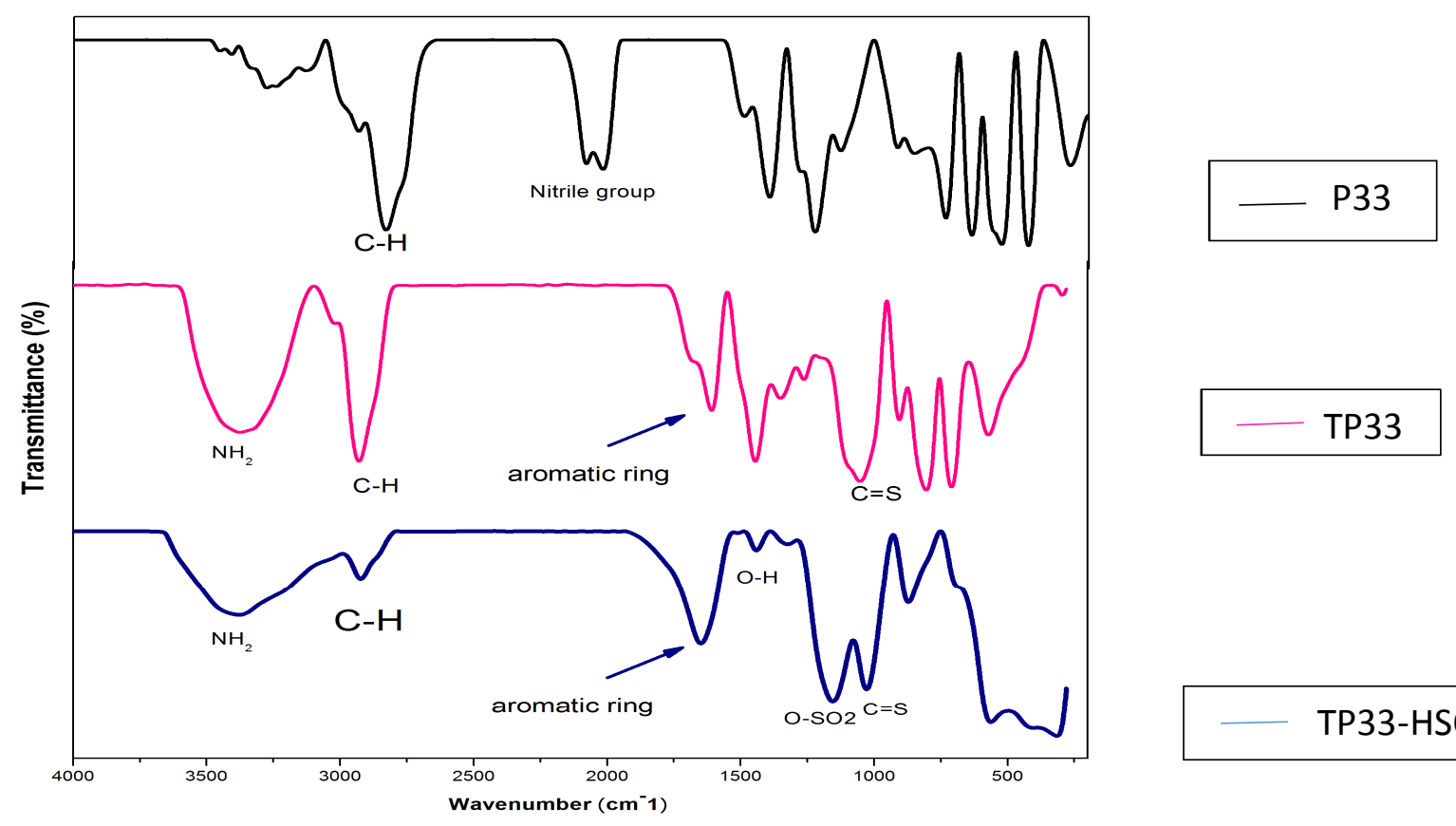

Figure 9 IR Spectra of poly (AN-co-DVB-80), thioamide-modified poly (AN-co-DVB-80) and thioamide- $\mathrm{HSO}_{3}$-modified poly (AN-co-DVB-80)

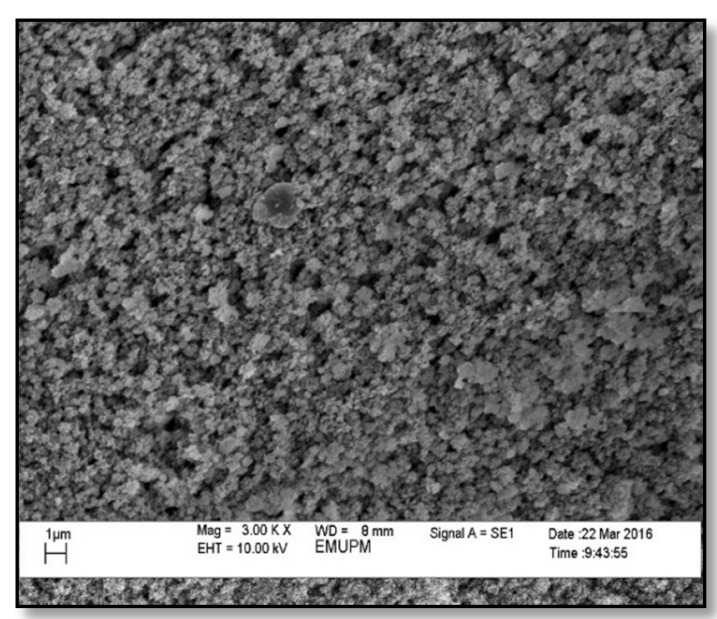

P29 poly (AN-co-DVB80) $(1.00: 0.0)$

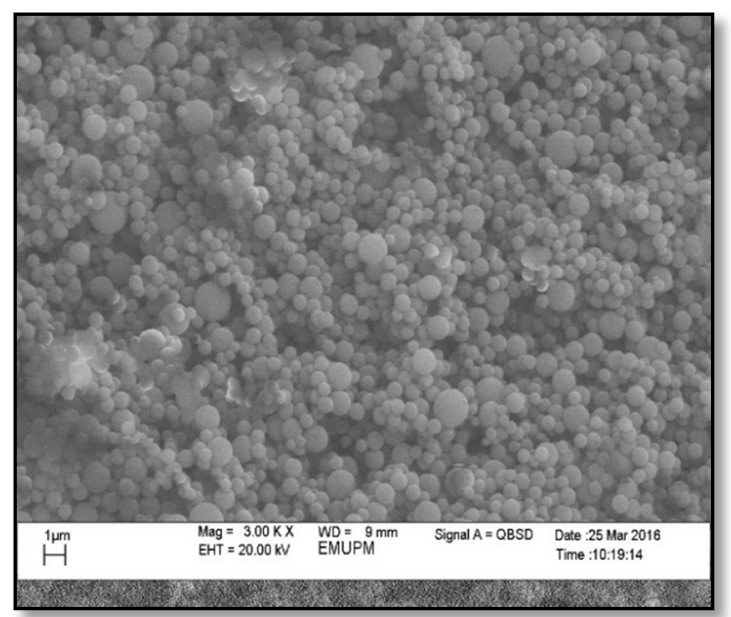

P35 poly (AN-co-DVB80) $(0.0: 1.00)$

Figure 10 SEM images of poly (AN) and poly (DVB-80) 


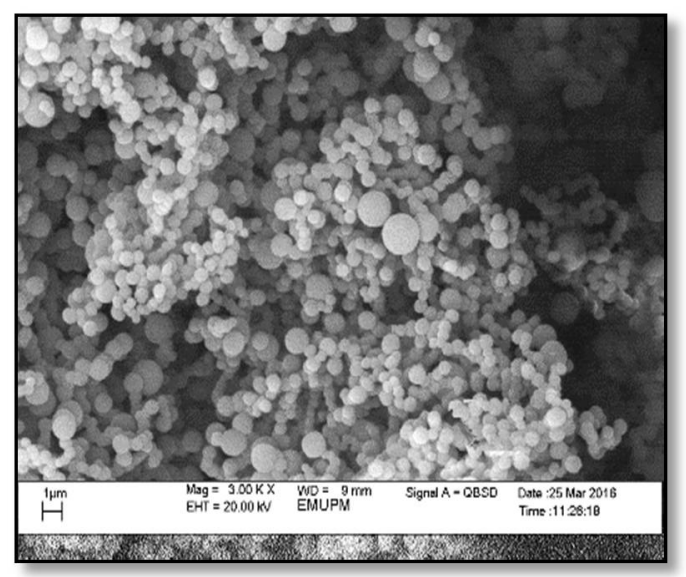

P30 poly (AN-co-DVB-80)

0.20:0.80

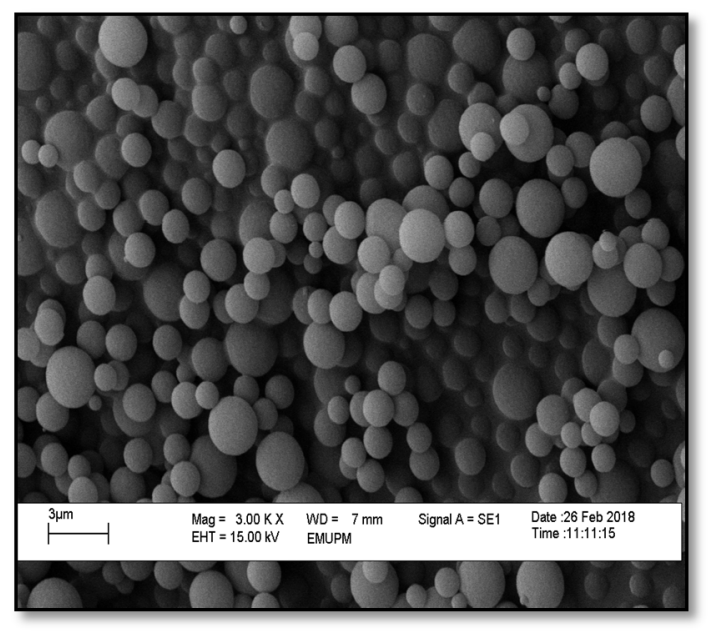

P32 poly (AN-co-DVB-80)

0.40:0.60

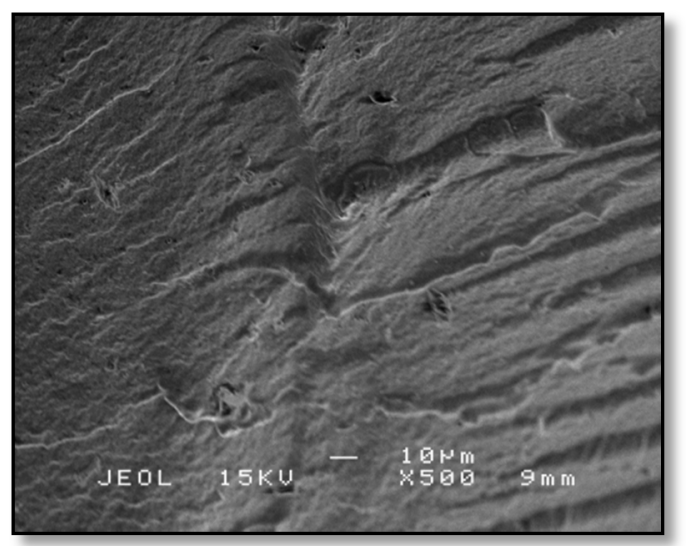

P34 poly (AN-co-DVB-80)

0.80:0.20

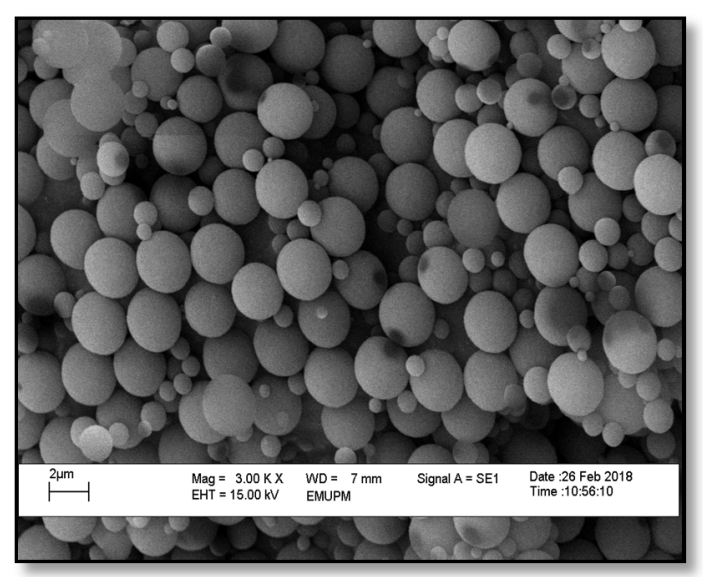

P31 poly (AN-co-DVB-80)

$0.25: 0.75$

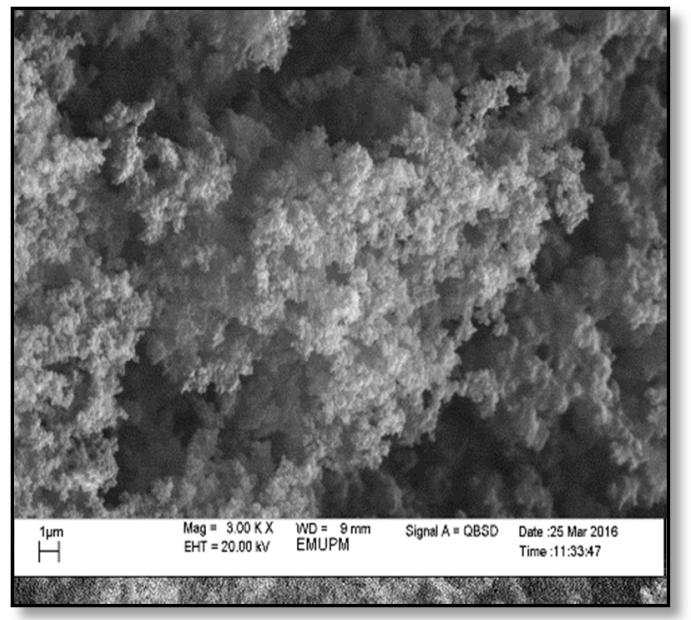

P33 poly (AN-co-DVB-80)

0.50:0.50

Figure 11 SEM images of poly (AN-co-DVB-80) with different AN/DVB-80 ratios 


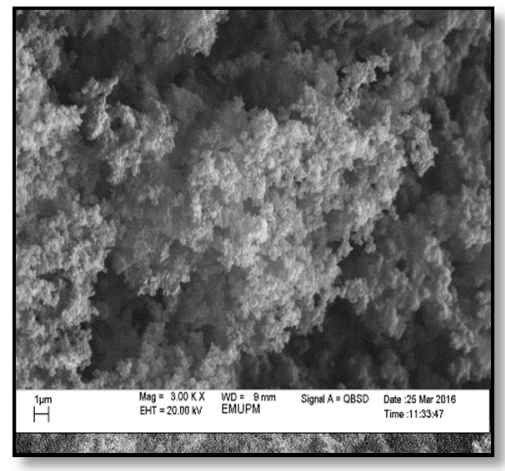

P33 poly (AN-co-DVB-80)

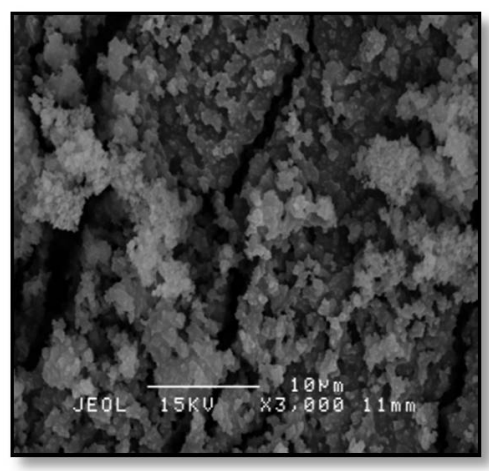

TP33 thioamide-modified poly (AN-co-DVB-80)

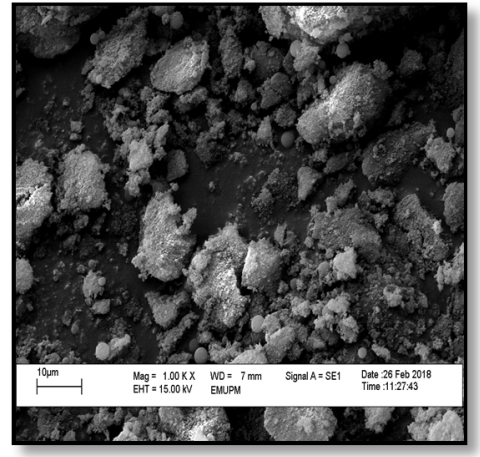

TP33- $-\mathrm{HSO}_{3}$ thioamidemodified poly (AN-co-DVB80)- $\mathrm{HSO}_{3}$

Figure 12 SEM images of poly (AN-co-DVB-80), thioamide-modified poly (AN-co-DVB-80), and thioamide- $\mathrm{HSO}_{3}$-modified poly (AN-co-DVB-80)

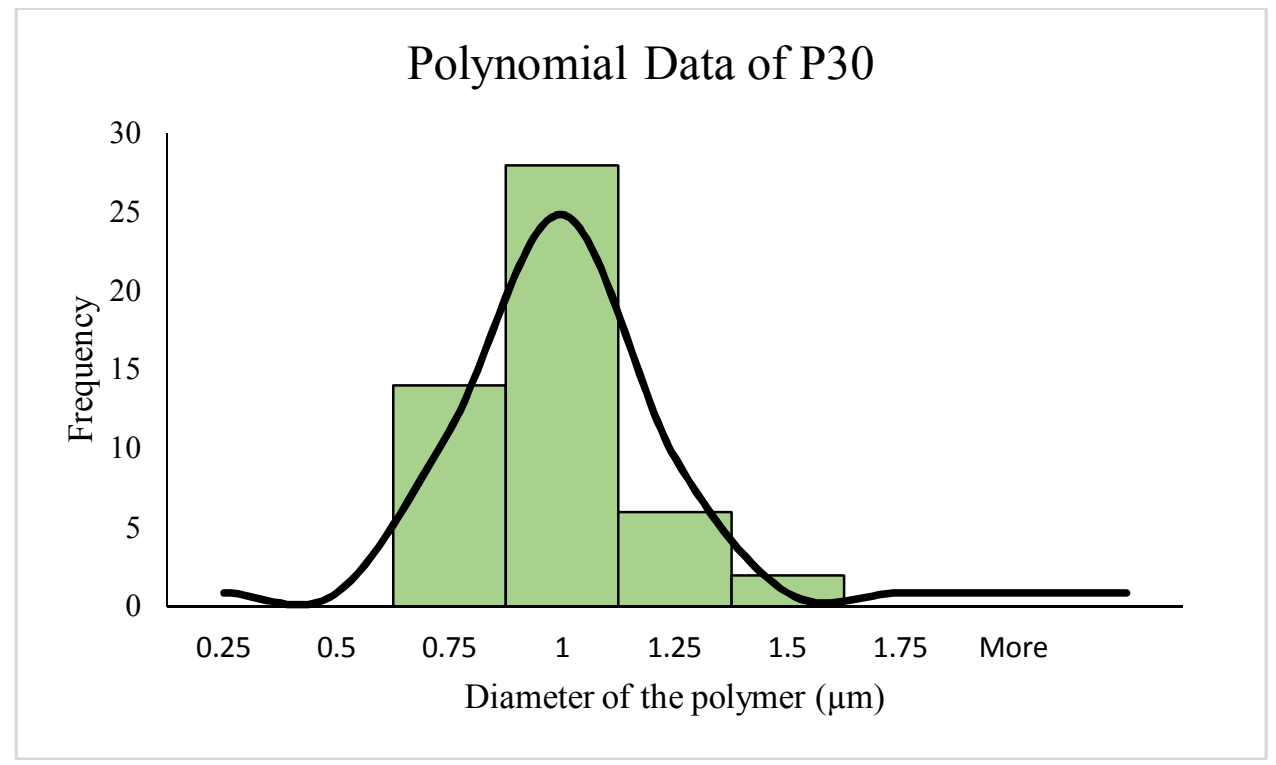

(a) 


\section{Polynomial Data of P31}

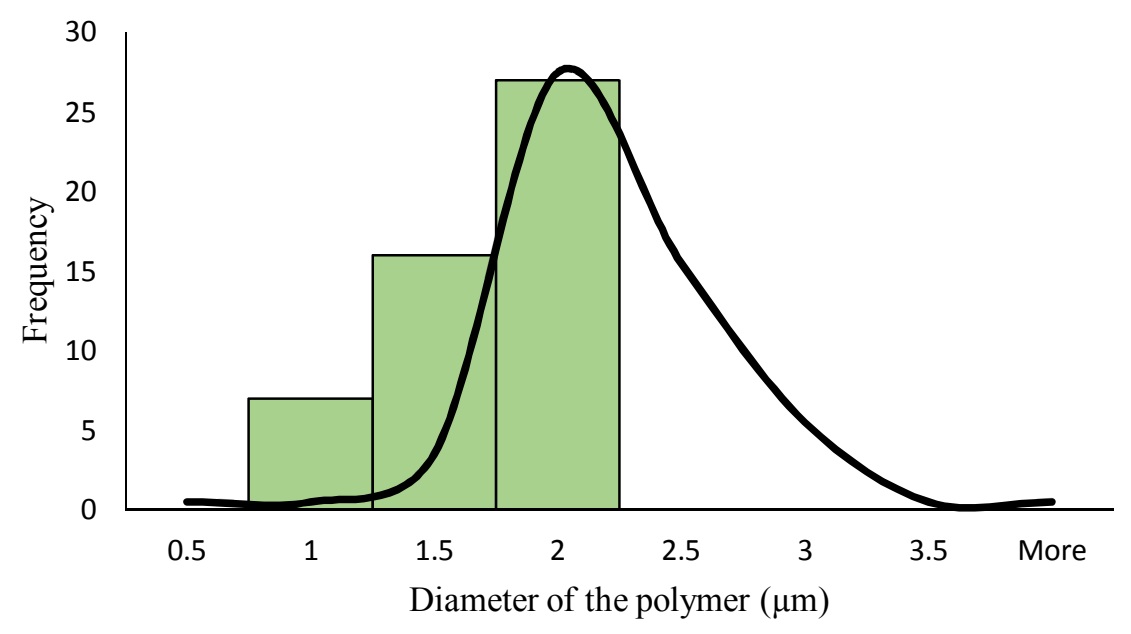

(b)

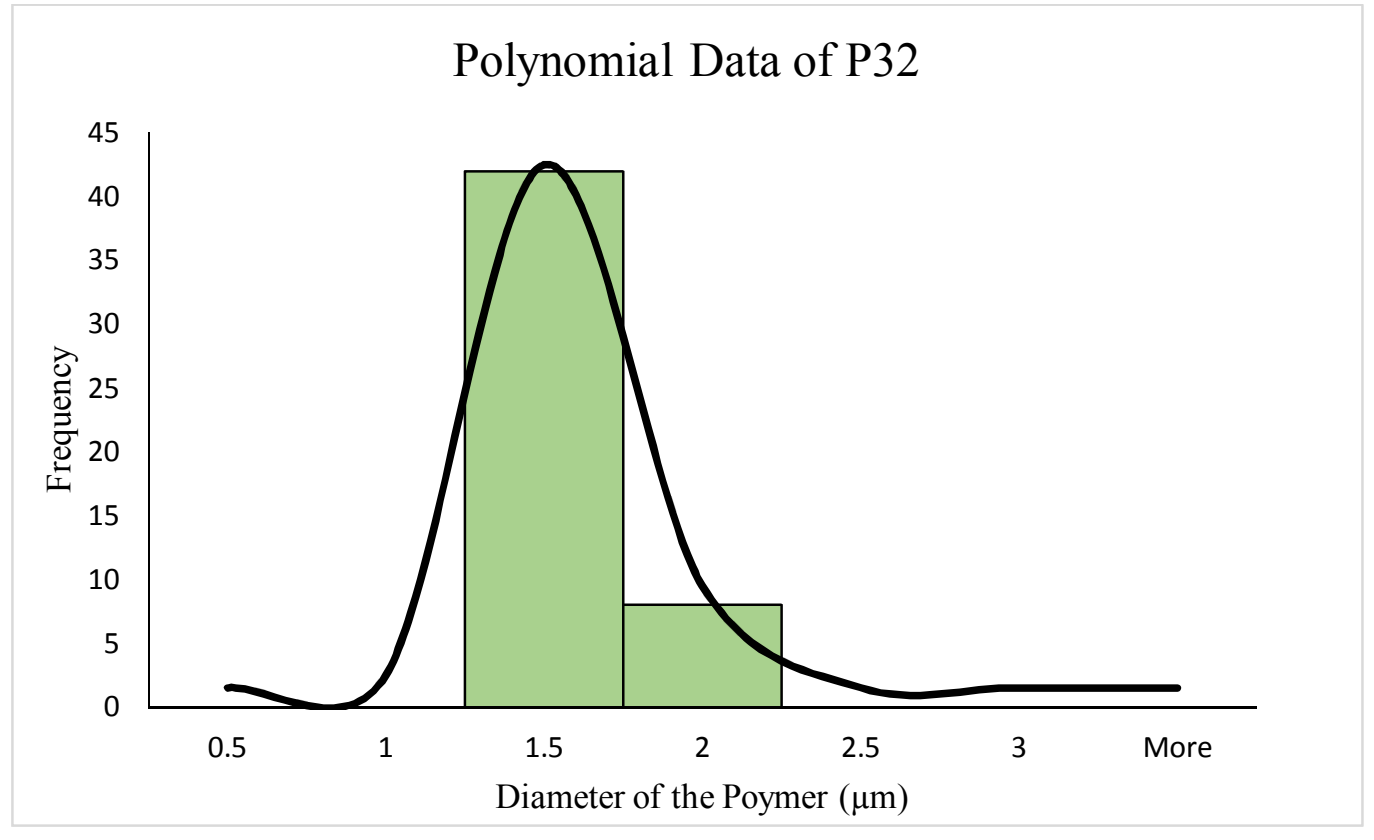

(c)

Figure 13 Polynomial Data of (a) P30, (b) P31 and (c) P32 


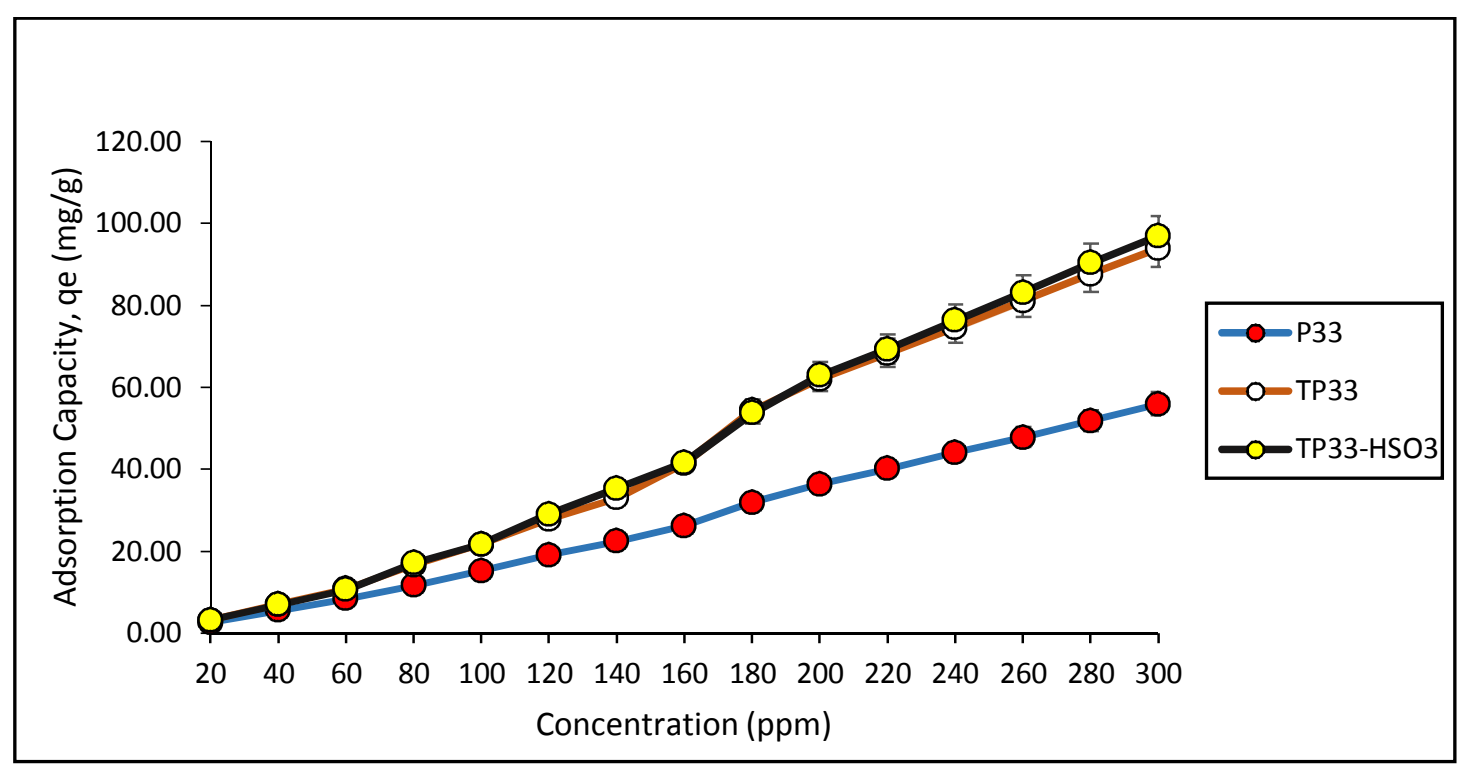

(a)

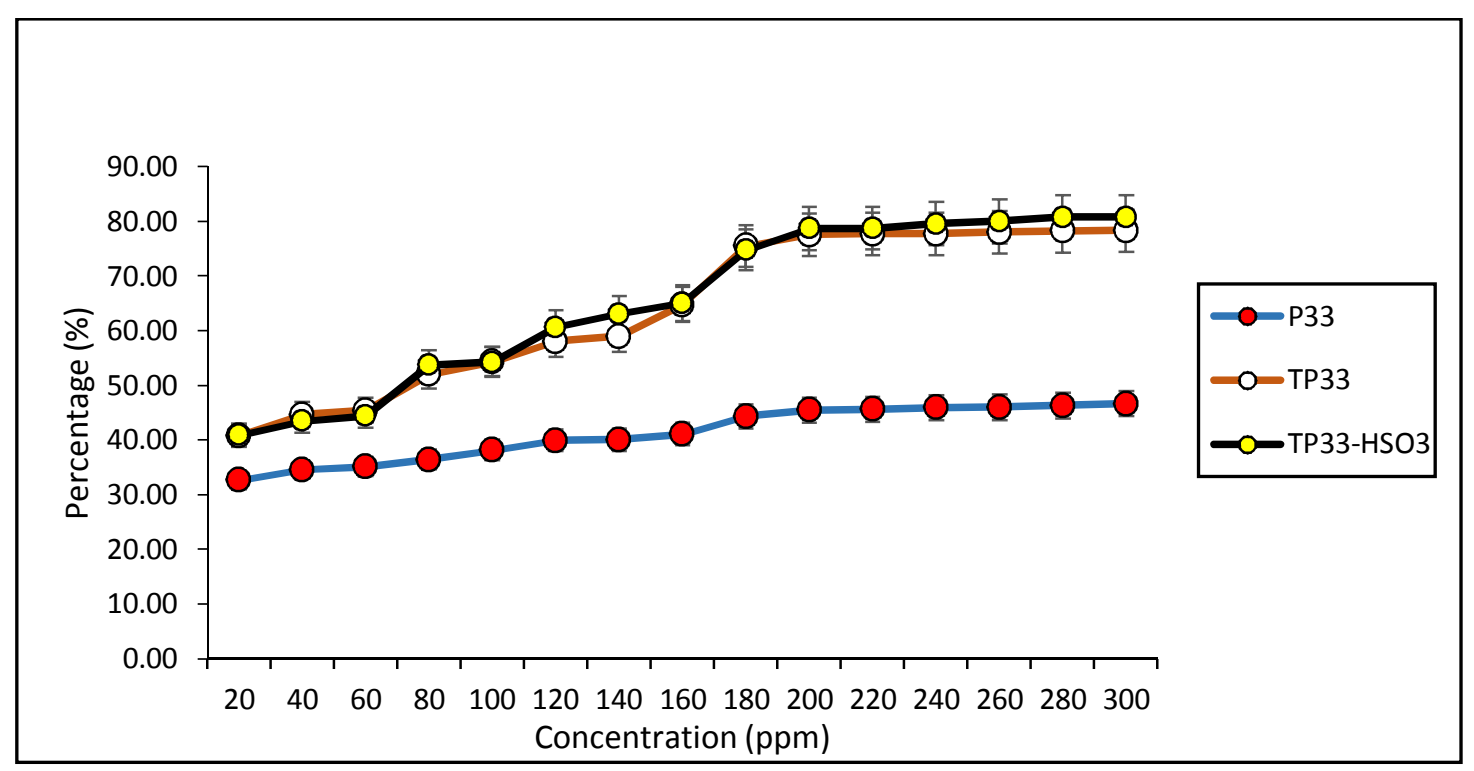

(b)

Figure 14 (a) Adsorption capacity and (b) percentage of mefenamic acid (MA) adsorbed by sorbents at different MA concentration

Experimental condition: $50 \mathrm{mg}$ of sorbent, $20 \mathrm{~mL}$ of sample volume, $24 \mathrm{~h}$ of contact time, stirred at $4500 \mathrm{rpm}$ under room temperature

P33 = poly (AN-co-DVB-80), TP33 = thioamide-modified poly (AN-co-DVB-80), TPP- $\mathrm{HSO}_{3}=$ thioamide- $\mathrm{HSO}_{3}$-modified poly (AN-co-DVB-80) 


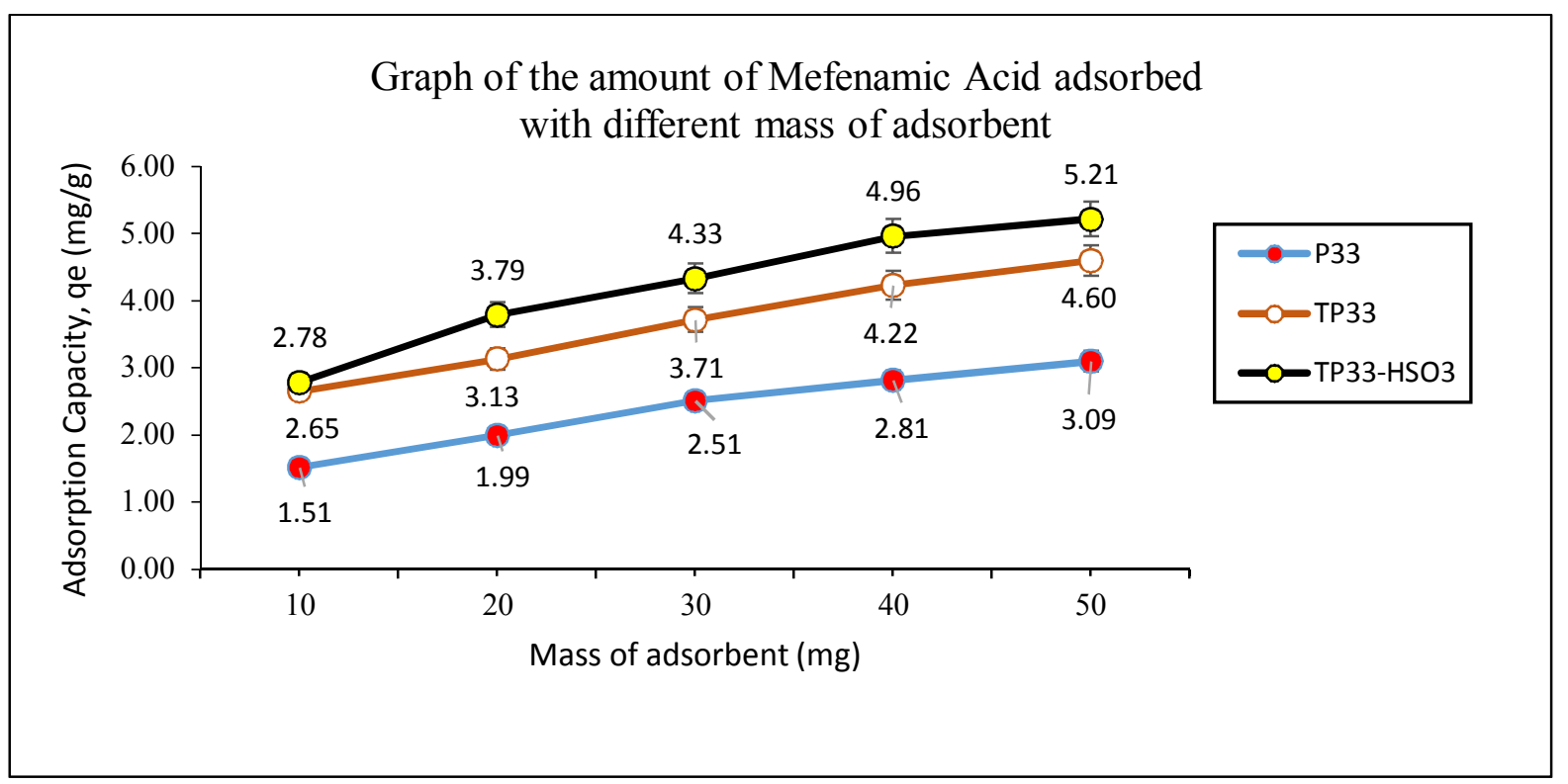

(a)

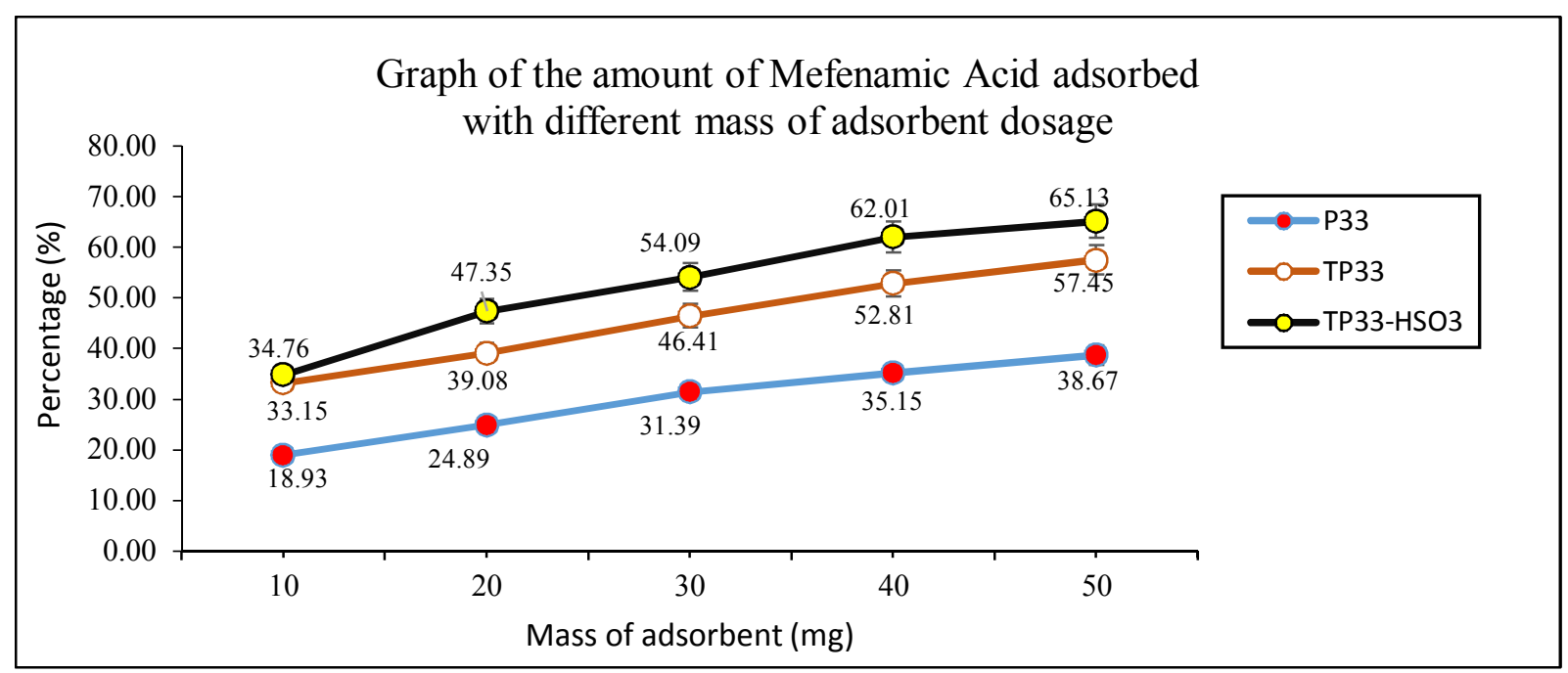

Figure 15 (a) Adsorption capacity and (b) percentage of mefenamic acid adsorbed by sorbents at different sorbent dosage

Experimental condition: 20 ppm of mefenamic acid, $20 \mathrm{~mL}$ of sample volume, $24 \mathrm{~h}$ of contact time, stirred at $4500 \mathrm{rpm}$ under room temperature

P33 = poly (AN-co-DVB-80), TP33 = thioamide-modified poly (AN-co-DVB-80), TPP- $\mathrm{HSO}_{3}=$ thioamide- $\mathrm{HSO}_{3}$-modified poly (AN-co-DVB-80) 


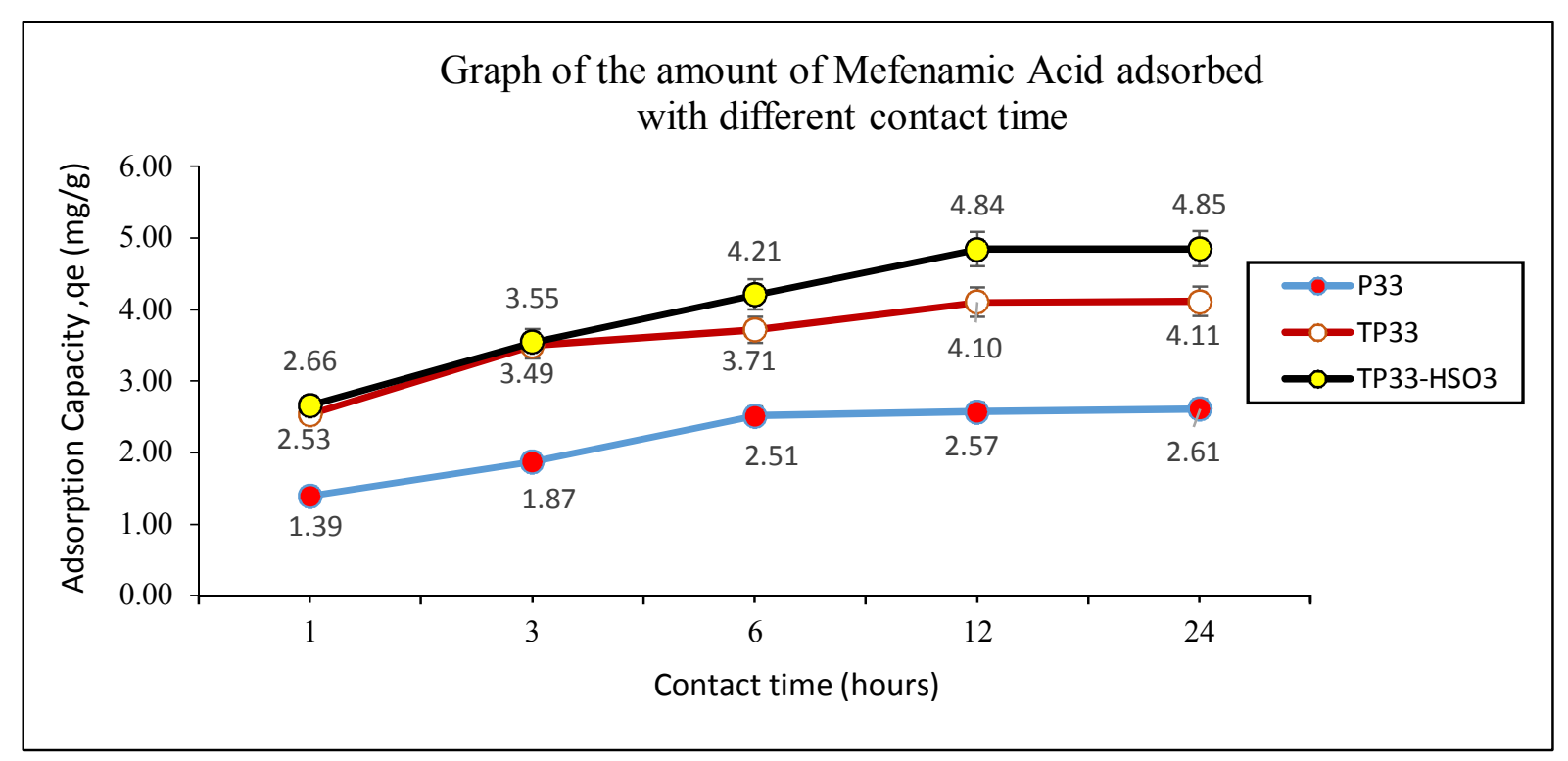

(a)

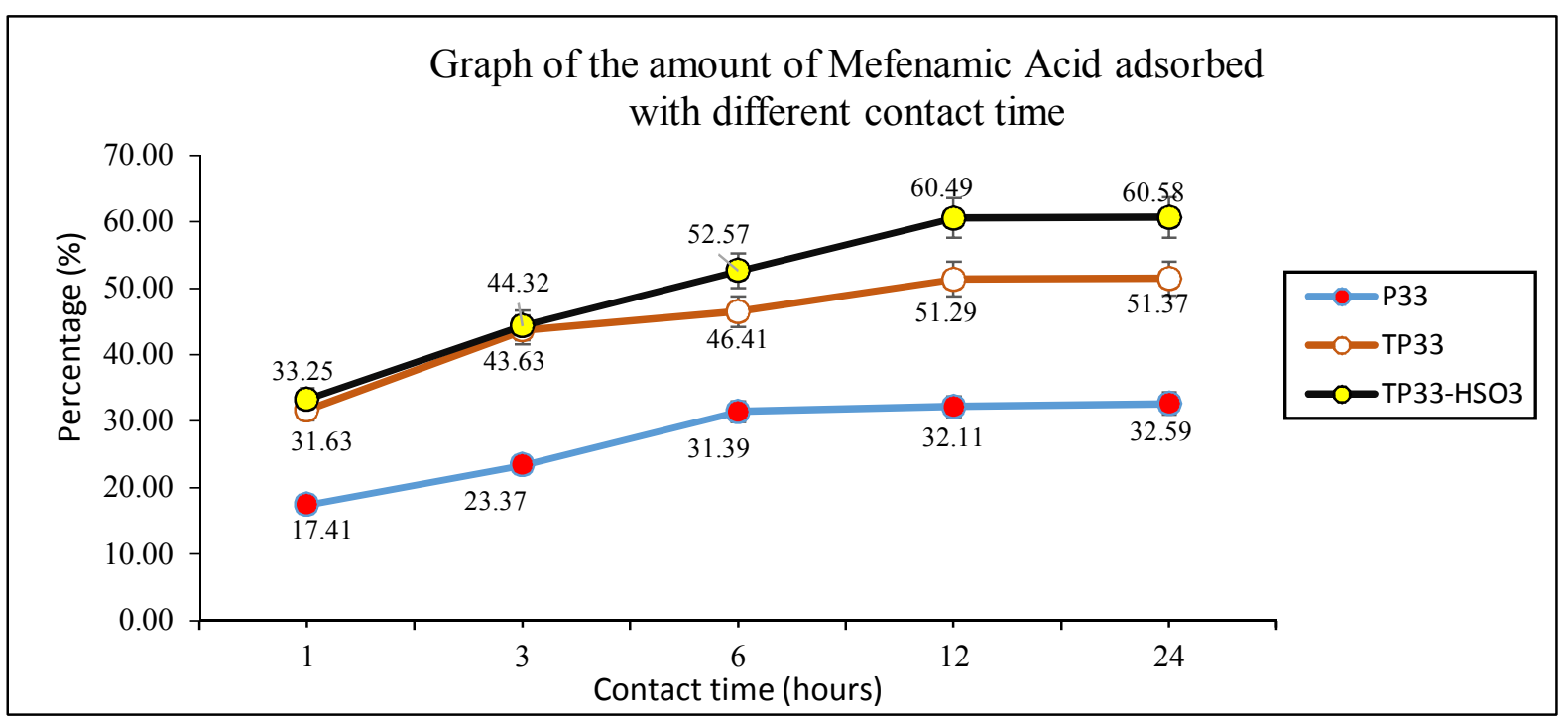

Figure 16 (a) Adsorption capacity and (b) percentage of mefenamic acid adsorbed by sorbents at different contact time

Experimental condition: $50 \mathrm{mg}$ of sorbent, $20 \mathrm{ppm}$ of mefenamic acid, $20 \mathrm{~mL}$ of sample volume, stirred at $4500 \mathrm{rpm}$ under room temperature $\mathrm{P} 33$ = poly (AN-co-DVB-80), TP33 = thioamide-modified poly (AN-co-DVB-80), TPP- $\mathrm{HSO}_{3}=$ thioamide- $\mathrm{HSO}_{3}$-modified poly (AN-co-DVB-80) 
Table 1 Concentration of pharmaceuticals detected in Langat River and STPs effluents (ngL ${ }^{-1}$ ) [11]

\begin{tabular}{ccc}
\hline & \multicolumn{2}{c}{ Concentration, ngL } \\
Analyte & River Water & STPs effluent \\
\hline Acetaminophen & 10 & 70 \\
Amlodipine & $<\mathrm{MDL}$ & $<\mathrm{MDL}$ \\
Atenolol & 46 & 107 \\
Chlorpheniramine & $<\mathrm{MDL}$ & $<\mathrm{MDL}$ \\
Cyproterone & $<\mathrm{MDL}$ & $<\mathrm{MDL}$ \\
Loratadine & $<\mathrm{MDL}$ & $<\mathrm{MDL}$ \\
Lovastatin & $<\mathrm{MDL}$ & 10 \\
Metformin & 293 & 16 \\
Metoprolol & $<\mathrm{MDL}$ & 364 \\
Nifedipine & $<\mathrm{MDL}$ & $<\mathrm{MDL}$ \\
Norethindrone & $<\mathrm{MDL}$ & 188 \\
Levonogestrel & 38 & $<\mathrm{MDL}$ \\
Perindopril & 8 & 16 \\
Salbutamol & $<\mathrm{MDL}$ & 3 \\
Simvastatin & $<\mathrm{MDL}$ & $<\mathrm{MDL}$ \\
Chlorothiazide & 182 & 865 \\
Diclofenac & 17 & 217 \\
Furosemide & 9 & 175 \\
Glibenclamide & 2 & 5 \\
Gliclazide & 4 & 65 \\
Mefenamic acid & 13 & 146 \\
Salicylic acid & 34 & 36 \\
\hline
\end{tabular}

Table 2 Monomers in feed for the synthesis of poly (AN-co-DVB-80) in a mixture of acetonitrile and toluene

\begin{tabular}{ccccc}
\hline Sample & AN mole fraction & DVB-80 mole fraction & AN, mL & DVB-80, mL \\
\hline P30 & 0.20 & 0.80 & 0.4566 & 3.9034 \\
P31 & 0.25 & 0.75 & 0.5906 & 3.7867 \\
P32 & 0.40 & 0.60 & 1.0551 & 3.3821 \\
P33 & 0.50 & 0.50 & 1.4299 & 3.0557 \\
P34 & 0.80 & 0.20 & 3.0608 & 1.6352 \\
\hline
\end{tabular}


Table 3 Yields of the polymerisation of poly (AN-co-DVB-80) with different ratios

\begin{tabular}{ccc}
\hline Sample & Mole fraction of AN: DVB-80 & Yields, $\%$ \\
\hline P29 & $0: 1.00$ & 45.60 \\
P30 & $0.20: 0.80$ & 88.80 \\
P31 & $0.25: 0.75$ & 82.68 \\
P32 & $0.40: 0.60$ & 80.56 \\
P33 & $0.50: 0.50$ & 78.00 \\
P34 & $0.80: 0.20$ & 68.80 \\
P35 & $1.00: 0$ & 25.50 \\
\hline
\end{tabular}

Table 4 IR wavenumber of poly (AN-co-DVB-80), thioamide-modified poly (AN-co-DVB-80) and thioamide-modified poly (AN-co-DVB-80)- $\mathrm{HSO}_{3}$

\begin{tabular}{|c|c|c|c|}
\hline Functional groups & $\begin{array}{c}\text { Poly (AN-co-DVB- } \\
\text { 80) }\end{array}$ & $\begin{array}{c}\text { Thioamide } \\
\text { modified poly } \\
\text { (AN-co-DVB-80) }\end{array}$ & $\begin{array}{c}\text { Thioamide modified } \\
\text { poly (AN-co-DVB-80)- } \\
\mathrm{HSO}_{3}\end{array}$ \\
\hline & \multicolumn{3}{|c|}{ Wavenumber, $\mathbf{c m}^{-1}$} \\
\hline NH2 & - & $3347.90-3360.29$ & $3347-3360.29$ \\
\hline СН, СH2, СH3 & $2800-3000$ & $2925.22-2928.81$ & $2925.22-2928.81$ \\
\hline $\mathbf{C} \equiv \mathbf{N}$ & 2173.32 & - & - \\
\hline $\mathbf{C}=\mathbf{O}$ & 1700 & - & - \\
\hline $\mathrm{C}=\mathrm{N}-\mathbf{O}$ & $1502.47-1505.04$ & - & - \\
\hline $\mathrm{HNC}=\mathrm{S}$ & - & $940-1140$ & $940-1140$ \\
\hline $\mathbf{C}=\mathbf{S}$ & - & $1050-1200$ & $1050-1200$ \\
\hline $\mathrm{C}=\mathrm{C}$ aromatic ring & $1600-1650$ & $1600-1650$ & 1649.49 \\
\hline $\mathrm{O}_{-\mathrm{SO}_{2}}$ & - & - & 1154.47 \\
\hline O-H (weak band) & - & - & 1440.69 \\
\hline
\end{tabular}

Table 5 Size and dispersity of poly (AN), poly (DVB-80) and poly (AN-co-DVB-80)

\begin{tabular}{ccccc}
\hline Sample & $\begin{array}{c}\text { Mole fraction of } \\
\text { AN: DVB-80 }\end{array}$ & $\begin{array}{c}\text { Mean particle diameter, } \\
\boldsymbol{\mu m}\end{array}$ & $\begin{array}{c}\text { Coefficient of } \\
\text { variation, } \%\end{array}$ & $\begin{array}{c}\text { Dispersity, } \\
\mathbf{C}_{\mathbf{v}}\end{array}$ \\
\hline P35 & $1.00: 0$ & Agglomerated clusters & - & - \\
P34 & $0.80: 0.20$ & Lumps & - & - \\
P33 & $0.50: 0.50$ & Small particles & - & - \\
P32 & $0.40: 0.60$ & 1.50 & 22.50 & polydisperse \\
P31 & $0.25: 0.75$ & 1.93 & 40.04 & polydisperse \\
P30 & $0.20: 0.80$ & 0.93 & 27.13 & polydisperse \\
P29 & $0: 1.00$ & 1.09 & 33.80 & polydisperse \\
\hline
\end{tabular}


Table 6 BET data of the poly (AN-co-DVB-80) with different ratios

\begin{tabular}{ccccc}
\hline Sample & $\begin{array}{c}\text { Mole fraction of } \\
\text { AN: DVB-80 }\end{array}$ & $\begin{array}{c}\text { Surface area, } \mathbf{~ m}^{\mathbf{2}} \mathbf{g}^{-\mathbf{1}} \\
\text { Volume pores, } \\
\mathbf{c m}^{\mathbf{3}} \mathbf{g}^{\mathbf{- 1}}\end{array}$ & $\begin{array}{c}\text { Pore size, } \\
\mathbf{n m}\end{array}$ \\
\hline P30 & $0.20: 0.80$ & 793 & 0.823 & 2.3 \\
P31 & $0.25: 0.75$ & 762 & 0.763 & 2.8 \\
P32 & $0.40: 0.60$ & 627 & 0.528 & 3.2 \\
P33 & $0.50: 0.50$ & 565 & 0.467 & 5.8 \\
P34 & $0.80: 0.20$ & 27 & 0.159 & 23.9 \\
\hline
\end{tabular}

Table 7 BET data of the poly (AN-co-DVB-80), thioamide-modified poly (AN-co-DVB-80) and thioamide-modified poly (AN-co-DVB-80)- $\mathrm{HSO}_{3}$

\begin{tabular}{ccccc}
\hline Sample & $\begin{array}{c}\text { Mole fraction of } \\
\text { AN: DVB-80 }\end{array}$ & $\begin{array}{c}\text { Surface area, } \\
\mathbf{~ m}^{\mathbf{2}} \mathbf{g}^{-\mathbf{1}}\end{array}$ & $\begin{array}{c}\text { Volume pores, } \\
\mathbf{c m}^{\mathbf{3}} \mathbf{g}^{-\mathbf{1}}\end{array}$ & $\begin{array}{c}\text { Pore size, } \\
\mathbf{n m}\end{array}$ \\
\hline P33 & & 565 & 0.673 & 5.8 \\
TP33 & $0.50: 0.50$ & 330 & 0.582 & 7.0 \\
TP33-HSO $_{3}$ & & 4 & 0.554 & 552.8 \\
\hline
\end{tabular}

Table 8 Elemental Microanalysis data of poly (AN), poly (DVB80) and poly (AN-co-DVB-80) with different ratios

\begin{tabular}{cccccccc}
\hline & & \multicolumn{6}{c}{ Elemental Microanalysis (\%) } \\
\cline { 3 - 8 } Sample & Mole fraction of & \multicolumn{3}{c}{ C } & \multicolumn{3}{c}{ H } \\
\cline { 3 - 8 } & AN: DVB80 (\%) & Expected & Found & Expected & Found & Expected & Found \\
\hline P29 & $0: 100$ & 91.6 & 88.3 & 8.0 & 7.8 & 0.3 & 0.2 \\
P30 & $0.20: 0.80$ & 90.0 & 85.2 & 7.6 & 7.3 & 2.4 & 2.7 \\
P31 & $0.25: 0.75$ & 89.4 & 83.6 & 7.5 & 7.2 & 3.2 & 3.0 \\
P32 & $0.40: 0.60$ & 87.1 & 84.8 & 7.3 & 7.3 & 5.6 & 4.6 \\
P33 & $0.50: 0.50$ & 85.2 & 81.7 & 7.2 & 7.1 & 7.6 & 5.1 \\
P34 & $0.80: 0.20$ & 77.2 & 75.5 & 6.5 & 6.7 & 16.4 & 9.7 \\
P35 & $1.00: 0$ & 67.9 & 66.7 & 5.7 & 5.7 & 26.4 & 26.3 \\
\hline
\end{tabular}


Table 9 Elemental Microanalysis data of poly (AN-co-DVB-80), thioamide-modified poly (AN-co-DVB-80), and thioamide- $\mathrm{HSO}_{3}$-modified poly (AN-co-DVB-80)

\begin{tabular}{cccc}
\hline \multirow{2}{*}{$\begin{array}{c}\text { Type of } \\
\text { composition }\end{array}$} & \multicolumn{3}{c}{ Sample } \\
\cline { 2 - 4 } & $\mathbf{3 3 3}$ & TP33 & TP33-HSO $_{3}$ \\
\cline { 2 - 4 } & 81.7 & 76.26 & 50.96 \\
$\mathbf{C}$ & 7.1 & 7.1 & 6.076 \\
$\mathbf{N}$ & 5.1 & 5.7 & 3.31 \\
$\mathbf{S}$ & 1.6 & 4.0 & 5.827 \\
\hline
\end{tabular}

